\title{
1 Research trends in the use of remote sensing for inland 2 water quality science: Moving towards multidisciplinary 3 applications
} \\ Simon Topp ${ }^{* 1}$, Tamlin Pavelsky ${ }^{1}$, Daniel Jensen ${ }^{2,4}$, Marc Simard ${ }^{2}$, Matthew R.V. Ross ${ }^{3}$ \\ ${ }^{1}$ Department of Geological Sciences, University of North Carolina at Chapel Hill, 104 South Rd, Mitchell Hall, \\ Chapel Hill, NC 27599 \\ 2 NASA Jet Propulsion Laboratory, 4800 Oak Grove Dr, Pasadena, CA 91109 \\ ${ }^{3}$ Department of Ecosystem Science and Sustainability, Colorado State University, 1476 Campus Delivery, Fort \\ Collins, CO 80523 \\ ${ }^{4}$ Department of Geography, University of California at Los Angeles, Los Angeles, CA 90095, USA \\ * Corresponding Author - Simon Topp (Email: sntopp@live.unc.edu, Tel: 303-917-2694) \\ -Tamlin Pavelsky (pavelsky@email.unc.edu) \\ -Daniel Jensen (daniel.j.jensen@jpl.nasa.gov) \\ -Marc Simard (marc.simard@jpl.nasa.gov) \\ -Matthew Ross (ㅍrvr@rams.colostate.edu)
}

Abstract: Remote sensing approaches to measuring inland water quality date back nearly 50 years to the beginning of the satellite era. Over this time span, hundreds of peer reviewed publications have demonstrated promising remote sensing models to estimate biological, chemical, and physical properties of inland waterbodies. Until recently, most of these publications focused largely on algorithm development as opposed to implementation of those algorithms to address specific science questions. This slow evolution contrasts with terrestrial and oceanic remote sensing, where methods development in the 1970s led to publications focused on understanding spatially expansive, complex processes as early as the mid-1980s. This review explores the progression of inland water quality remote sensing from methodological development to scientific applications. We use bibliometric analysis to assess overall patterns in the field and subsequently examine 236 key papers to identify trends in research focus and scale. The results highlight an initial 30-year period where the majority of publications focused on model development and validation followed by a spike in publications, beginning in the early-2000s, applying remote sensing models to analyze spatiotemporal trends, drivers, and impacts of changing water quality on ecosystems and human populations. Recent and emerging resources, including improved data availability and enhanced processing platforms, are enabling researchers to address challenging science questions and model spatiotemporally explicit patterns in water quality. Examination of the literature shows that the past 10-15 years has brought about a focal shift within the field, where researchers are using improved computing resources, data sets, and operational remote sensing algorithms to better understand complex inland water systems. Future satellite missions promise to continue these improvements by providing observational continuity with spatial/spectral resolutions ideal for inland waters.

Keywords: remote sensing, water quality, lakes, rivers, inland waters, scientific advancement 


\section{Introduction}

Remote sensing has long been promised as a tool for large-scale monitoring of inland water quality. Dating back to the early 1970s, airborne and satellite sensors have been used to examine a wide range of water quality constituents [1,2]. In the 50 years since, scientists have produced hundreds of peer reviewed publications presenting models estimating biological, chemical, and physical properties of complex waterbodies (see reviews [3-6]). Despite this proliferation of publications, existing reviews focus almost exclusively on methodological approaches rather than on the scientific contributions of remote sensing to our understanding of water quality, so characterization of the extent to which remote sensing has improved our knowledge of inland water dynamics remains limited.

The historical tendency of inland water remote sensing to focus largely on methods development (here defined as data collection and processing and/or algorithm calibration and validation), contrasts starkly with that of related fields in terms of both the scope of research questions and the scale of studies. For terrestrial remote sensing, algorithm development throughout the 1970s (e.g. Normalized Difference Vegetation Index (NDVI) [7]) led to publications focused on spatially expansive, complex processes as early as the mid-1980s. These papers include studies on global land use [8], global vegetation analysis [9], and connections between primary productivity and carbon cycling [10,11]. For ocean color remote sensing, early methods development led to global datasets and estimations of oceanic primary productivity by the late 1980s [12,13]. Comparatively, global data products for inland water quality are limited, with a few key exceptions (e.g. [14]) despite widespread acknowledgement of their importance from the inland water scientific community $[15,16]$. This slow evolution can be partially explained by well-known challenges related to remote sensing of complex waterbodies, as well as the limited availability of sensors appropriate for inland water quality remote sensing [17], discussed in detail with other challenges in section 7 .

Previous reviews have provided excellent summaries of the technical approaches available to retrieve inland water quality parameters through remote sensing, as well as the current limitations of the field [36,18-20]. Instead, we focus not on methodological details, but on the overall purpose and impact of past publications, how those impacts have changed over time, and how the field may evolve in the future. We quantify broad-scale trends through bibliometric analysis of search engine results. A subset of the most relevant published papers $(n=236)$ was identified using existing reviews, citation counts, database queries, and journal-specific searches. The identified papers were subsequently read, with key attributes documented in order to analyze trends and patterns in methodological approaches, model application, research focus, and study scale over time. Here, trend refers to a pattern with directionality over time or space. We limit our analysis to airborne and satellite remote sensing publications focusing on lakes, rivers, deltas, and estuaries, although we fully acknowledge that these publications were preceded by years of vital methods development using handheld and shipborne sensors (e.g. [21-26]). Similarly, given the focus of this paper on the remote sensing of lake, river, delta, and estuarine systems, which present their own unique challenges [17], we excluded studies on near shore ocean waters and the Laurentian Great Lakes.

Our results highlight a nearly 30-year period focusing predominantly on methods development prior to a spike in publications, beginning in the early 2000s, applying well validated algorithms to identify spatiotemporal trends, drivers, and impacts of changing inland water quality on ecosystem functions and human populations. Study scale exhibits a similar trend towards increasingly large areas with more waterbodies studied over longer periods of time, slowly moving closer to regional and global-scale data products. Through both broad and detailed inspection of the field, our results suggest that the past decade of inland water remote sensing has led to a fuller understanding of inland water processes by focusing on 
challenging science questions and increased study scales. This contribution continues today with an everexpanding body of available data, processing platforms, and methodologies.

We contextualize our analysis of the literature by: 1) summarizing the primary water constituents measured with earth observation instruments, 2) providing a brief overview of common modelling approaches to measure those constituents, and 3) discussing the limitations that have hampered past research. This contextual information is followed by the bibliometric and index analysis described above. We conclude with a discussion of potential future directions for the field.

\section{Earth observation sensors and optically active waterbody constituents}

The work reviewed here focuses primarily on passive optical satellite sensors capable of large-scale remote sensing research. In general, these are either ocean color sensors such as the Moderate Resolution Imaging Spectroradiometer (MODIS) [29-32], the Medium Resolution Imaging Spectrometer (MERIS) [3336], and the Sentinel-3 Ocean and Land Cover Instrument (OLCI) [37], or land surface optical sensors including the Landsat series (Multispectral Scanner (MSS): [38-40]; Thematic Mapper (TM): [41-43]; Enhanced Thematic Mapper (ETM+): [44-46]; and Operational Land Imager (OLI): [47,48]), Sentinel $2 \mathrm{~A} / \mathrm{B}$ MultiSpectral Instrument (MSI) [49,50], and SPOT High Resolution Geometric Sensor (HRG) [51]. A subset of researchers have used high resolution commercial sensors including WorldView 2 [52] and IKONOS [53,54]. The above sensors vary significantly in their applicability based largely on their spatial, temporal, spectral, and radiometric resolutions. Temporal and spatial resolutions determine the scale of processes that can be captured by a given sensor. In general, land surface sensors have a finer spatial resolution $(\sim 10 \mathrm{~m}-30 \mathrm{~m})$ but coarser temporal resolution ( 1-2 weeks), allowing them to detect spatial patterns in water quality in smaller waterbodies (e.g. small lakes and rivers) but with only 1-2 observations per month depending on the sensor and cloud cover conditions. Comparatively, ocean color sensors are characterized by coarse spatial resolutions $(\sim 300-1000 \mathrm{~m})$ but finer temporal resolutions ( daily), limiting observations to large waterbodies but facilitating examination of processes that occur at short timespans. A more in-depth discussion on the effects of varying resolutions across ocean and terrestrial sensors can be found in Olmanson, Brezonik, \& Bauer (2011)[55] and CEOS (2018)[56] .

Since water is highly absorptive within the near and shortwave infrared spectrum, the majority of water-leaving radiance occurs within the visible spectrum with slight variations dependent on temperature and salinity $[57,58]$. The primary exception is in optically complex waters (due to high turbidity and/or bottom reflectance), where sediment reflectance exceeds the absorptive properties of water in the near and shortwave infrared wavelengths [51,59]. Relatively high absorption within the visible spectrum leads to a low range of reflectance values when compared to land surface remote sensing. This low range requires high sensitivity (i.e. high radiometric resolution) to detect small changes in reflectance [4]. Different concentrations of varying water quality parameters lead to various absorption and backscattering peaks within the water leaving radiance. The spectral resolution, measured by the range of wavelengths captured by individual sensor bands, needs to be sufficiently fine to capture spectral peaks and accurately estimate the contribution of a given water quality parameter to the overall spectral signature [17]. The sensors mentioned above are all multispectral sensors, meaning that they have a small number of relatively wide bands $(\sim 10 \mathrm{~nm}$ to $\sim 80 \mathrm{~nm})$ placed within the visible to mid-infrared spectrum. These coarse bandwidths can complicate retrieval of water quality parameters [17]. In order to better capture the specific absorption and backscattering peaks within a waterbody's spectral signature, a subset of publications have utilized hyperspectral sensors that provide hundreds of narrow (1- $10 \mathrm{~nm})$, contiguous bands spanning the visible to shortwave infrared spectrum (see [60]). Currently, the majority of hyperspectral sensors are airborne or in planning stages for future satellite missions [61]. Within inland water remote sensing, applications of hyperspectral remote sensors include the use of Hyperion [62,63], the 
Compact Airborne Spectrographic Imager (CASI) [64,65], the Airborne Prism Experiment (APEX) [66], and NASA's HyMAP scanner [67], Airborne Visible/Infrared Spectrometer (AVIRIS) [68], Airborne Visible/Infrared Spectrometer-Next Generation (AVIRIS-NG) [69], and Portable Remote Imaging Spectrometer (PRISM) [70].

Regardless of sensor, the optically active water parameters that contribute to the total water-leaving signal are phytoplankton, organic and inorganic suspended sediments, and colored dissolved organic matter (CDOM). [59,71,72]. The sum of these three individual constituents, in combination, attribute to differences in overall water clarity, which is frequently used as a proxy for water quality [15,73]. Publications leveraging relationships between optically inactive constituents, which have no detectable spectral signal, and the optically active constituents listed above have provided remote sensing models for nitrogen and phosphorous [74-76], dissolved oxygen [41,49], and heavy metals [77]. However, compared to optically active parameters, these optically inactive constituents require site specific algorithms due to varying regional correlations with optically active water quality constituents. Publications examining the remote sensing of inactive constituents date back to the early 90s [42,78]; however, they appear relatively infrequently within the literature and are not discussed in detail here. Below, we describe the optically active constituents with their distinct spectral signatures.

\subsection{Chlorophyll-a}

Chlorophylls are the photosynthetically active compounds that convert light into energy for photosynthesis. Remote sensing studies primarily focus on chlorophyll-a (chl-a), which is the most abundant chlorophyll and is present within all plants, algae, and cyanobacteria that photosynthesize. In aquatic systems, it is used as a proxy measure of total algal biomass [79]. The algal biomass of a waterbody controls its overall biological productivity, also known as trophic state, making it an ideal indicator of ecosystem integrity [80,81]. While not all algal blooms are inherently harmful, blooms containing certain species, most commonly phycocyanin-producing cyanobacteria, are toxic to humans, livestock, and wildlife [82]. Anthropogenically driven nutrient loading and climate change in recent decades have increased the size and frequency of these harmful algal blooms worldwide [83].

Optically, the spectral signature of chl-a varies depending on its concentration in relation to other water quality parameters and the composition of phytoplankton phenotypes producing the signal $[84,85]$. For low biomass, oligotrophic to mesotrophic waterbodies, the chl-a spectrum is characterized by a suninduced fluorescence peak around $680 \mathrm{~nm}$ [86-88]. For high biomass, eutrophic waterbodies, the florescence signal is masked by absorption and backscattering peaks centered at $665 \mathrm{~nm}$ and $710 \mathrm{~nm}$ respectively [89]. The ratio between these two wavelengths has been used to accurately estimate chl-a concentrations in numerous studies [90-92]. Beyond basic constituent retrieval, research focusing on chlorophyll includes the detection of harmful cyanobacteria [93-95] and phycocyanin [64,96], assessment of trophic state $[46,47,97]$, and algal bloom development and dispersion modelling [98-101].

\subsection{Total Suspended Solids}

Total suspended solids refer to both inorganic and organic particles held in suspension throughout a water column. Controls on the composition of organic and inorganic particles vary geographically, with some areas driven primarily by inorganic sediments and others by phytoplankton. In the literature it is referred to variously as total suspended matter, suspended sediment concentration, and particulate matter, though the precise definitions of these terms sometimes vary. Monitoring TSS fluxes has strong implications for biogeochemical cycling in terms of nutrient transport [102], heavy metal loading [103], light conditions [104], and global carbon budgets [105]. Terrestrial carbon deposition into lakes and reservoirs, largely in the form of TSS, is double that of deposition into the ocean $[106,107]$, despite lakes 
comprising only $3 \%-3.7 \%$ of the total land area $[108,109]$. Simultaneously, the settling out of TSS into lake bottom sediments provides a carbon sink, with current global carbon sequestration estimates ranging from 0.06-0.27 Pg year-1 $^{-1} \quad[105,107]$. On a local scale, high TSS reduces light penetration through increasing turbidity and leads to benthic smothering, impacting species composition and primary productivity from macrophytes [110,111]. Finally, TSS concentrations and flux in rivers capture the landscape processes controlling delivery of erosional products from land to ocean [112,113].

Spectral signatures of TSS concentrations can vary significantly based on the particle size and composition of organic to inorganic materials $[114,115]$. Organic-dominated systems derive their spectral signatures from algae concentrations and can share the pronounced absorption and backscattering peaks described above for chlorophyll [116]. As inorganic TSS concentrations increase within a waterbody, the location of the spectral maximum moves from around $550 \mathrm{~nm}$ into the red or near-infrared wavelengths [51] with waterbody specific variation dependent on chlorophyll and CDOM concentrations. Remote sensing studies examining TSS focus largely on riverine and coastal systems, with notable studies including estimates of TSS delivery to the ocean [112], variability in sediment plume size $[28,30,117]$, impacts of reservoirs on sediment concentration [118], impacts of land use change on sediment delivery [119], and variability of sediment in lagoons [120]. TSS concentrations can be correlated with various optically inactive water quality parameters and have subsequently been used to infer the concentration of phosphorous [3], mercury [119], and other metals [67] at local scales.

\subsection{Colored Dissolved Organic Matter}

Colored (or 'chromophoric') dissolved organic matter is the colored portion of total dissolved organic carbon. Sources of CDOM can be either autochthonous (i.e. phytoplankton) or allochthonous (i.e. terrestrial carbon). Of the two sources, allochthonous carbon leached out of surrounding soils is generally the dominant control of total lake and river dissolved organic carbon [121]. Photo and biodegradation of $\mathrm{CDOM}$ can contribute to elevated levels of $\mathrm{CO}_{2}$ within lacustrine systems [122]. Recent studies of $\mathrm{CO}_{2}$ concentrations in Chinese [123] and US [124] lakes found that $\sim 60-70 \%$ were supersaturated with $\mathrm{CO}_{2}$. Globally, this oversaturation leads to $0.35-0.43$ Pg year- $^{-1}$ of carbon off-gassed into the atmosphere, in

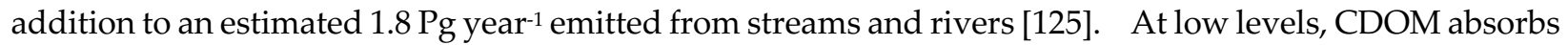
harmful ultraviolet radiation with minimal impact on light penetration within the visible spectrum [126]. As concentrations increase, absorption of low-wavelength light by CDOM regulates the light availability of primary producers, controlling net productivity and trophic structure [126,127]. Continued monitoring of CDOM directly, and as a proxy for total dissolved organic carbon, provides a better understanding of carbon inputs and processing in freshwater systems.

Highly absorptive in the visible spectrum, elevated levels of CDOM lead to stratified, dark waterbodies with limited light penetration [128]. Similar to TSS, the reflectance spectra of waterbodies with varying concentrations of CDOM are highly dependent on the composition of other optically active constituents, and in certain areas can be complicated by the presence of colloidal iron, which shares similar optical properties [129]. CDOM's contribution to water-leaving radiance is characterized by an exponential increase in absorption as wavelength decreases [130]. Intuitively, this would suggest that CDOM models should incorporate wavelengths in the blue spectrum; however, excessive absorption by CDOM and low natural water-leaving radiance at low wavelengths reduces the usable signal [24,131]. As a result, algorithms commonly incorporate a green/red ratio (e.g. [49,132-134]). Remote sensing studies focusing on CDOM range in application from identifying trends in inland water carbon content $[135,136]$ to examining landscape-level drivers of CDOM distributions [52,137]. Work in rivers highlights controls of carbon export in arctic landscapes [138] and relationships governing CDOM variation in river estuaries 
along with the resulting impact on correlated concentrations of methylmercury [70]. An in depth review of CDOM and its optical properties was published by Coble (2007) [139].

\subsection{Water Clarity}

The combination of chlorophyll, suspended sediments, and CDOM collectively contribute to overall water clarity. Most commonly, Secchi Disk depth or turbidity are used as relative measures of clarity. The former metric, developed more than 150 years ago, quantifies the maximum visible depth of a white and black disk lowered into a waterbody $[140,141]$. In comparison, turbidity is an explicit measurement of light scattering within a water column caused by suspended and dissolved particles. Water clarity regulates freshwater ecosystems through light attenuation and control over epilimnion depth [142]. Numerous studies have examined the role of water clarity in thermal stratification [143,144], lake metabolism [145,146], and biodiversity [110]. Generally, a shallower thermocline and reduced light penetration associated with degraded water clarity reduces photosynthesis of submerged macrophytes and other primary producers [110,147].

Remote sensing retrievals of water clarity almost universally use wavelengths and band ratios that include the red spectrum in some way (e.g. [73,78,148-153]). Reflectance at these wavelengths accounts for total sediment and chlorophyll concentrations such that increasing brightness is associated with decreased water clarity [4]. Water clarity has long been acknowledged as a proxy for nutrient availability and chlorophyll concentrations within lakes [154-156]; as a result, remote sensing studies frequently use it as a proxy for overall lake trophic status (oligotrophic, mesotrophic, or eutrophic) $[97,157,158]$.

\section{Modelling approaches}

Models that leverage the relationship between a waterbody's optical qualities and its concentration of optically active water quality constituents are commonly referred to as bio-optical algorithms [153]. In inland waters, these models can be categorized as empirical, semi-analytical, or machine learning based. While inherently empirical, we distinguish machine learning techniques separately due to their computational complexity and ability to handle non-linear relationships. As discussed below, all three of these modeling approaches have benefits and shortcomings in terms of applicable scale, model transparency, and model complexity.

\subsection{Empirical models}

The most common approach to inland water remote sensing involves fitting a standard linear regression between spectral band/band ratio values and temporally coincident in situ water quality measurements. One inherent limitation of this approach is its non-generalizability across large spatial and temporal scales where variations in atmospheric and water composition create large variability in observed spectral signatures of water quality parameters. As such, empirical models are restricted to confident predictions only within the range and setting of the input data. This restriction limits their application across spatiotemporal domains. At a local scale, empirical modelling accounts for the site-specific optical qualities of the water, but with increasing spatial or temporal scales, optically non-homogenous waterbodies and changing atmospheric conditions complicate parameterization [159]. These shortcomings are often outweighed by the benefits of model transparency, simplicity, and minimal computational requirements.

The family of empirical models can be split into purely empirical and semi-empirical approaches. The purely empirical approach derives relationships using input band and band ratio values as coefficients, often generating multiple models and choosing the best fit through comparison of error metrics. Purely 
empirical approaches date back to the 1970s and 80s, with notable applications examining trophic state in Wisconsin [2] and Minnesota [75], and turbidity and chlorophyll in Australian lakes [160].

In contrast, semi-empirical models use multi-band index values with some basis in the physical

\subsection{Semi-analytical models}

Analytical and semi-analytical models are physics based and involve parameterization based on the inherent optical properties (IOPs) of water and the atmosphere, where IOPs refer to the optical properties of the medium of interest that are independent of the ambient light field [59,71]. The IOPs of a given waterbody are modelled in coordination with apparent optical properties (including illumination conditions, sensor orientation, and field of view) to construct theoretical absorption and backscattering values which can then be decomposed through an inverse equation to estimate optically active water quality constituents (described below)[18,59,72,166]. For purely analytical models, the inverse equation is parameterized based purely on light physics; however, these are rarely used for optically complex waters where the interactions of numerous water quality constituents become difficult to model. As a result, semi-analytical models, which incorporate in situ measurements to parameterize the inverse equation, are the primary form of physics based algorithms developed for inland water quality remote sensing retrievals [4]. This modelling approach evolved from the reflectance approximation developed by Morel and Prieur (1977)[167], who studied turbidity and chlorophyll in ocean waters. Compared to empirical and semiempirical algorithms, semi-analytical models are mechanistic, make apriori assumptions regarding light physics, and are theoretically generalizable outside the range of a given study; however, the application of any single model to optically nonhomogeneous waterbodies requires large amounts of in situ validation data and remains challenging [16].

A prerequisite to this modelling approach is understanding the light physics that control reflectance as particle size, composition, and concentration vary. These properties are modelled through the absorption and backscattering coefficients of all the optically active constituents found within the study area (Eq. 1). While derivations of semi-analytical models come from numerous sources (e.g. [27,168170]), the basic form of the preliminary equation follows equation 1.

$$
\text { Eq. } 1 \quad R(\lambda)=Y^{*} \frac{b(\lambda)}{a(\lambda)+b(\lambda)}
$$

Here, the total reflectance just below the water's surface $(R)$ at wavelength $\lambda$ is equal to the backscattering at the given wavelength over the absorption plus the backscattering at the given wavelength times an empirically or analytically derived constant $Y$. The absorption and backscattering coefficients can be further broken down into absorption and backscattering for each optically active constituent. (e.g. 
$\left.b(\lambda)=b_{\text {water }}(\lambda)+b_{\text {cdom }}(\lambda)+(\lambda) b_{\text {chl }}+(\lambda) b_{\text {tss }}\right)$. Values for $R$ are either generated through in situ measurements of reflectance and water quality or theoretically generated using physical modelling software such as HydroLight [171]. These generated spectral signatures are then used to parameterize an inverse model that decomposes $R$ into optically active constituent concentrations through their absorption and backscattering coefficients. One benefit of this inverse modelling procedure is the ability to estimate multiple water quality parameters simultaneously. However, model development is inherently complicated and, depending on if atmospheric corrections have been applied, requires information about atmospheric composition, bottom reflectance, and extensive in situ sampling. Even so, the literature contains numerous examples of successful applications of semi-analytical models across large spatiotemporal scales. Early development of semi-analytical modelling for inland waters was led by researchers such as Dekker [26,172] and Kutser [173] examining chl-a, TSS, and CDOM. More recently, Heege et al. (2014)[174] developed a semi-analytical algorithm for turbidity across the Mekong Delta with strong validation results using MODIS, Landsat, and RapidEye, Lymburner et al. (2016)[175] applied a semi-analytical algorithm to a multi-decadal study of TSS in Australian lakes, and both Volpe et al. (2011)[120] and Zhou et al. (2017)[176] applied semi-analytical algorithms across multi- and hyper-spectral data to detect TSS in shallow lagoons. For a more detailed description of semi-analytical modelling see Dekker, Vos, \& Peters (2002)[178], Giardino et al. (2019)[18], Morel (2001)[166], and IOCCG (2000)[59].

\subsection{Machine learning models}

In recent years, increases in computational capacity and available data have created opportunities for novel approaches to data analysis. While inherently empirical, machine learning approaches are differentiated by their ability to operate in multidimensional space with complex non-linear relationships [179]. The spectrum of machine learning methods for remote sensing applications is broad [180,181]; here, we focus on the benefits and limitations of machine learning methods generally, along with some notable examples in the field of inland water remote sensing. A more detailed review of machine learning methodology for remote sensing was published by Lary et al. (2016)[181].

Within inland water remote sensing, machine learning algorithms including artificial neural networks [182-184], genetic algorithms/programming [185,186], support vector machines [187], random forest/boosted regression trees [188], and empirical orthogonal functions $[189,190]$ have all shown promise in accurately estimating water quality parameters across a variety of spatiotemporal scales. As with traditional empirical models, machine learning approaches are only applicable within the range and setting of data used to train a given model. However, unlike traditional empirical models, most machine learning models use iterative learning to reduce overall error and maximize model fit [191]. Depending on the parameterization of the model and the amount of training data available, this approach may lead to overfitting of the data, especially in models with numerous input variables subject to collinearity such as adjacent hyperspectral bands [192]. To avoid overfitting, machine learning methods require the provision of separate training and testing datasets that contain representative samples of the parameters of interest. The power and scalability of most machine learning algorithms is dependent on the quality and range of the training and testing data. Given the proper inputs, these algorithms can produce generalizable models that capture complex, non-linear relationships between remotely sensed reflectance and biogeophysical parameters. While modelling chl-a and turbidity in Lake Chagan, China, Song (2011)[183] found reductions in root mean square error of $76 \%$ and $65 \%$, respectively, when comparing traditional regression techniques to artificial neural networks. Similarly, Xiang et al. (2015)[193] found a 20\% increase in trophic state classification accuracy when using machine learning compared to multivariate regression.

\section{Challenges and limitations within the field}


Despite the diverse modelling approaches discussed above, several barriers still exist that limit the progress of inland water remote sensing. Sensor design, atmospheric effects, dynamic waterbodies, and institutional barriers all present legitimate challenges to increasing the scale and robustness of remote 311 sensing algorithms.

At the most basic level, many sensors are limited in the types of observations they can make. Multispectral, broad-band satellites like the Landsat TM/ETM+ series were engineered for terrestrial applications and lack the spectral resolution and band centers ideal for complex waters. Their relatively infrequent return periods make them more suited to detecting long-term changes as opposed to daily or weekly variation. Ocean color sensors including MODIS, SeaWiFS, and MERIS have higher spectral resolution and frequent return periods, but they lack the spatial resolution to capture narrower inland water bodies, particularly rivers (see $[4,17]$ for detailed discussion). The newest generation of sensors has been designed to overcome some of these issues [18,19], though the limited precision of broad spectral bands remains a challenge. While they lack certain band centers useful for inland water remote sensing, new sensors such as the Landsat 8 Operational Land Imager (OLI) and the Sentinel 2 MultiSpectral Instrument (MSI) have increased signal to noise ratios, improved radiometric and temporal resolution, and aerosol-specific bands making them better equipped to handle the size and complexity of inland waters [194,195].

Regardless of sensor choice, among the largest barriers to remote sensing of inland waters is controlling for varying atmospheric effects. The signal to noise ratio of top-of-atmosphere radiance over waterbodies can vary substantially with different atmospheric water vapor and aerosol concentrations. In order to accurately estimate water quality parameters, the atmospheric effects need to be controlled for through precise atmospheric corrections $[20,196]$. These corrections are particularly important over large spatiotemporal domains because atmospheric conditions can vary significantly. Historic correction procedures are largely based on open ocean remote sensing and assume zero water leaving radiance beyond the visible spectrum [197]. This assumption does not hold over optically complex waters where chlorophyll, suspended sediment, and bottom reflectance lead to true non-zero radiance in the near infrared. The result is an overestimation of aerosol thickness and an overcorrection of visible wavelengths in turbid waters [198]. Progress has been made improving atmospheric correction algorithms over complex waters through the use of radiative transfer functions [198], pseudo-invariant features [194], dark pixel extraction [199], and SWIR-based correction procedures [200,201]; however, many methods lack transferability between sensors making it difficult to compare surface reflectance products across platforms [202]. Atmospheric correction is further complicated by adjacency effects from surrounding land. Radiation reflected from relatively bright land is scattered by the atmosphere, increasing noise over adjacent, relatively dark waterbodies. Solving adjacency issues typically involves computationally expensive radiative transfer functions, though recent progress has been made using models that reduce computational requirements by approximating atmospheric scattering within the correction procedure [203].

Independent atmospheric challenges are exacerbated by the dynamic nature of waterbodies themselves. Changing water conditions and bio-fouling of in situ sensors can make it difficult to capture coincident field and satellite observations necessary for model development [204,205]. From a reflectance standpoint, algal mats, surface macrophytes, and sun glint (specular reflection of sunlight towards the sensor) all contribute extraneous signals to observed water-leaving radiance. The body of literature on these issues is significant, and processing schemes to isolate and/or remove these signals are continually improving. For sun glint, removal schemes can range from relatively simple empirical models such as those tested by Kutser, Vahtmäe, \& Praks (2009)[206] to more complicated radiative transfer functions [207]. 
Algal Index [163], Maximum-Peak Height [89], and adaptations of classic NDWI indexes [94] have all provided robust delineation of water from adjacent algal and macrophyte signals. Additionally, varying sediment types between regions can affect the relationship between reflectance and measurements of TSS [115]. These variations can be partially accounted for using band ratio algorithms that are generalizable across sediment types [208].

The above technical barriers represent legitimate challenges to extracting water quality constituents from dynamic inland systems. However, existing retrospectives on the past 50 years in the field indicate that technical barriers alone are not responsible for the slow progress towards applying remote sensing as a tool to better understand inland water systems. Bukata (2013)[209] insightfully proposes that one explanation may be the relatively isolated nature of the field and the historic lack of collaboration with related ocean color remote sensing. This observation is supported by Downing (2014)[210], who describes the fields of oceanography and limnology as "twins, mostly separated since birth". This lack of institutional communication has had ripple effects, reducing collaborative projects and limiting funding sources. Collaboration is further reduced through the inherent scale of the research. Technical challenges with spatiotemporally expansive studies generally constrain inland water research efforts to localized scales. This pattern contrasts with ocean remote sensing, where international study areas have led to numerous, well-funded, multinational research efforts [211]. Communication and collaboration leading to these large research efforts is facilitated by international organizations like the International Ocean-Colour Coordinating Group (IOCCG). Recent work done by the IOCCG [20], as well as emerging groups like AquaWatch (https://www.geoaquawatch.org/), are working towards similar goals for inland water remote sensing researchers, but these efforts are still in their infancy compared to their ocean color counterparts. The nature of the field and its apparent lack of cohesion may, in part, stem from the fact that it is spread across many different disciplines. A Scopus search query of inland water quality remote sensing returns publications from over 350 distinct journals spread across hydrology, ecology, biogeochemistry, environmental management, and engineering, indicating that much of the research is spread across different niches and sub-disciplines. However, the following examination of the literature indicates that these barriers, both technical and institutional, have been dramatically reduced over the past decade.

\section{Evolution of inland water remote sensing publications}

In order to analyze the progression of publications on remote sensing of inland water quality, we carried out two analyses: the first identifies general trends in publication patterns, while the second analyzes trends in modelling approaches and research focus. 
5.1 Overarching trends in the field of inland water remote sensing

General trends were identified through a bibliometric analysis of search results from the Elsevier Scopus database (conducted July 2018). Database titles, keywords, and abstracts were searched for the terms 'remote sensing', 'water quality', and either 'lake', 'reservoir', 'river', 'delta', 'estuary', or 'inland waters' (along with variants, i.e. 'lake' and 'lakes'). The search results returned 1,186 distinct articles published in peer reviewed journals dating back to 1970 (Figure 1). Bibliometric data was extracted from the query using the Bibliometrix package in $\mathrm{R}$ [212].

The results of the Scopus bibliometric analysis indicate that inland water quality remote sensing has been growing dramatically since

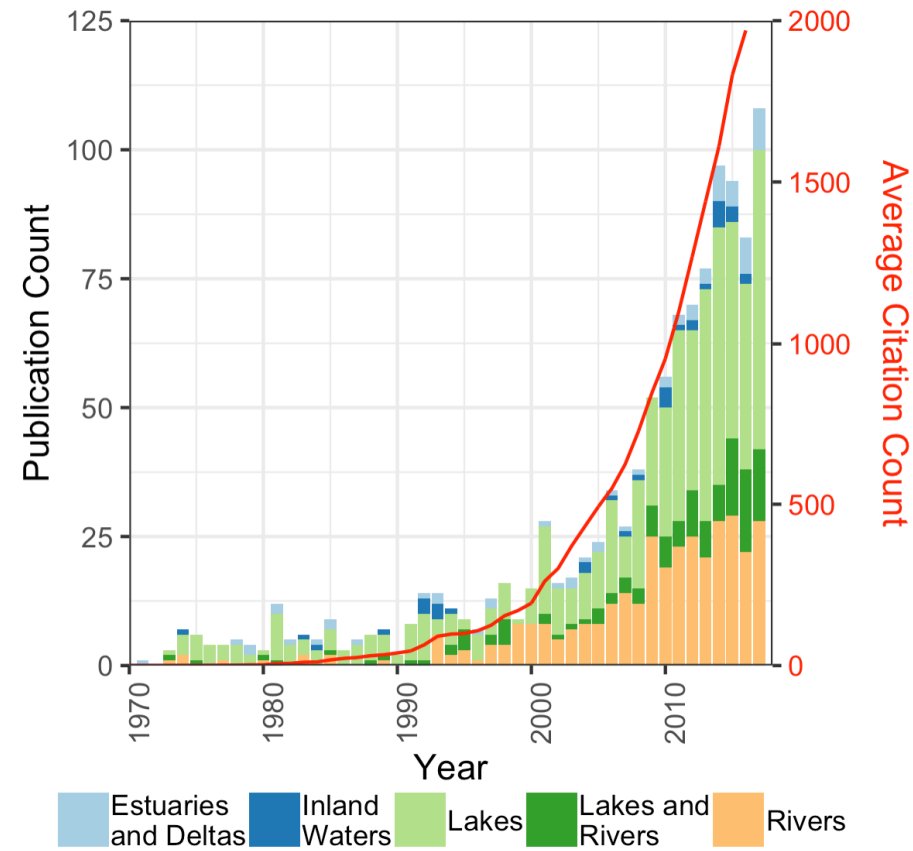

Figure 1. Published papers per year returned from Scopus search queries and grouped by search term. Average citation count is the sum of citations for all papers averaged over the number of years since their publication. its introduction in the 1970s. The annual average increase in publications over the study period is $8.9 \%$, but examination of the trend indicates that it is best represented by a simple power law function $\left(\mathrm{R}^{2}=0.848\right)$, with a sharp increase in publications starting in the early 2000s. Power law functions allow for the calculation of a doubling time which represents the amount of time it takes a population to double in size starting from any given timepoint. Bornmann \& Mutz (2015) calculated the doubling time and average annual growth rate for total academic publishing between 1980 and 2012 to be approximately 23.7 years and $2.96 \%$ respectively. For the same period, remote sensing of inland water quality grew at three times that rate, with a doubling time and average annual growth rate of 8.3 years and $10.01 \%$ respectively. The most pronounced yearon-year jump occurs right after 2008, which corresponds to the public release of freely available Landsat imagery by NASA and the US Geological Survey. After removing the overall trend of the power law function, a t-test on the residuals for the 5 years before and after 2008 indicates a significant increase in publications for the period after Landsat was made public ( $95 \% C I=0.3-0.7, p=0.0016)$. This result is consistent with previous research showing that for multiple earth observation fields, the release of the Landsat archive resulted in more frequent and larger-scale studies [214]. 
Further analysis of the bibliometric data shows that while contributions to the literature come from a diverse set of sources, there are a few distinct countries, journals, and authors that are disproportionately active within the field. Publications from the United States and China are responsible for $26.1 \%$ and $21.4 \%$ of the total publications respectively (Figure 2). Similarly, while there are contributions to the literature from 3,362 authors or co-authors, publications that include the top ten most productive authors comprise $17 \%$ of the total search results (Table 1). The cumulative contribution of publications from the top ten

Table 1. Summary data from Scopus query for inland water quality remote sensing.

\begin{tabular}{|l|r|}
\hline \multicolumn{2}{|c|}{ Scopus Query Summary } \\
Total Publications & 1186 \\
\hline Distinct Journals & 342 \\
\hline Distinct Key w ords (Scopus) & 7706 \\
\hline Distinct Key w ords (Authors) & 2447 \\
\hline Average citations per publication & 16.6 \\
\hline \multicolumn{2}{|c|}{ Authorship Summary } \\
Distinct Authors \\
\hline Authors per Documents \\
\hline \multicolumn{2}{|c|}{ Contributions Summary } \\
\hline Contribution from top 10 Countries & $676(54.8 \%)$ \\
\hline Contribution from top 10 Authors & $209(16.9 \%)$ \\
\hline Contribution from top 10 Journals & $378(30.6 \%)$ \\
\hline
\end{tabular}
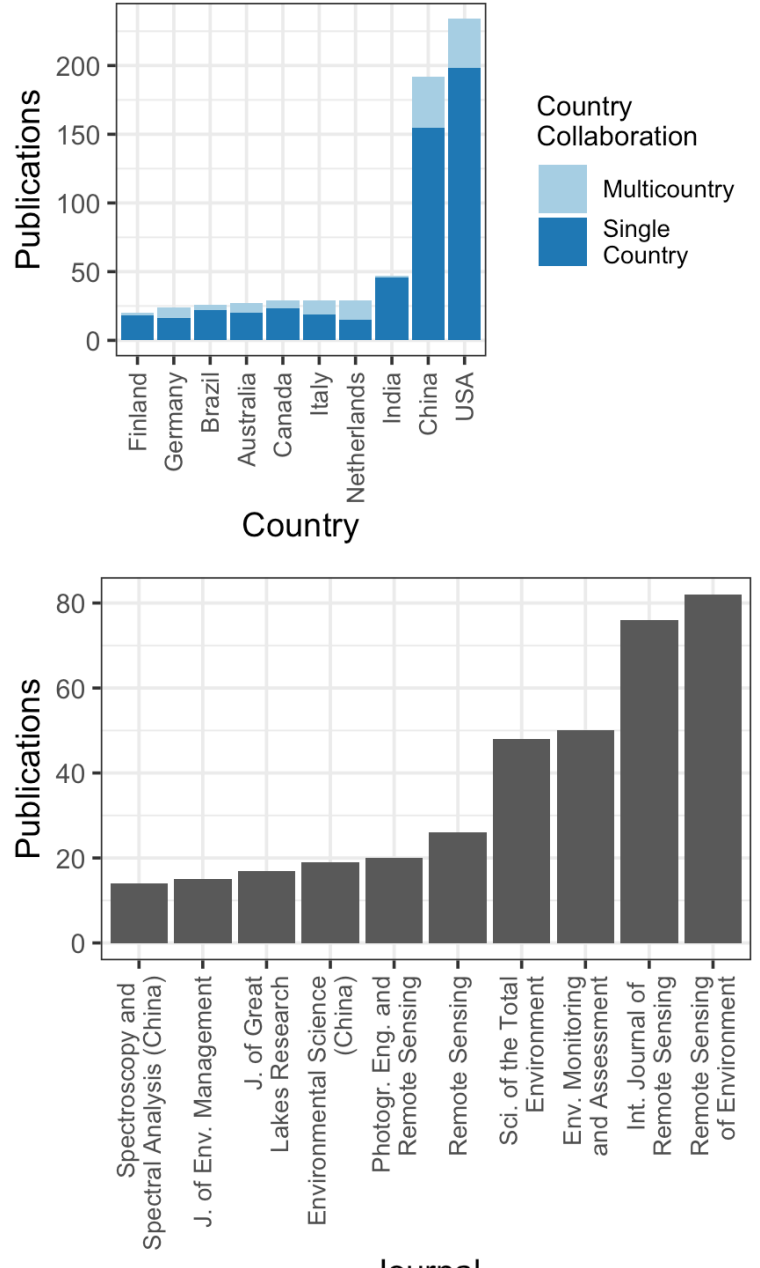

Journal

Figure 2. Distribution of publications returned from Scopus query for the top ten most productive countries and top ten most published journals. 
were chosen based on a combination of their search relevance, citation count, and subject focus. While we strived to be comprehensive in the inclusion of papers, some relevant studies were inevitably missed. We conducted more intensive journal-specific searches within high impact journals including Science, Nature, PNAS, WRR, Association for the Sciences of Limnology and Oceanography (ASLO) journals, and Ecological Society of America (ESA) journals to ensure the inclusion of studies that utilized remote sensing but focused more on scientific application of remote sensing than on methods development. A significant and worthwhile body of work exists using remote sensing to study water quality in complex near coast ocean environments as well as the Laurentian Great Lakes (see reviews [3-6]). While critical to the development of inland water quality remote sensing methods, this body of work was excluded from this review in order to better focus on lake, river, and estuary remote sensing applications and how those applications have changed over time. Similarly, studies using strictly in situ reflectance were excluded because our focus was on remote sensing from satellites or airborne platforms. The final subset was read to analyze overarching trends in research focus and scale. Each of the resulting 236 papers was subsequently classified into one of the four categories outlined below.

1. Purely methodological - The purpose of the paper is to present and validate a new model or methodology. Results consist of model validation and error metrics. No figures depicting spatial or temporal patterns are present.

2. Methodological with pattern analysis: The paper is predominately methods development and validation but includes some figures applying the proposed model either spatially or temporally.

3. Trend/pattern analysis: The purpose of the paper is to examine spatiotemporal patterns and/or trends in water quality within the study area, with trends defined has having directionality over space or time. Model validation results are presented for transparency, but the bulk of the results and discussion focusses on either spatial or temporal trend analysis. The preponderance of figures and tables depict maps, time-series, or other spatiotemporal analyses.

4. Water quality science research with a focus on impacts and drivers: The paper contains specific hypotheses and/or science questions to be directly addressed. Results and discussion focus on spatiotemporal dynamics of water quality as well as the drivers and/or impacts of changing water quality. The preponderance of figures and tables present within the paper depict either trends or relationships between the parameter of interest and associated drivers/impacts.

Key questions that determined the classification of the papers included:

1. Is there a specific hypothesis or science question addressed?

2. Is there any spatial or temporal analysis of patterns or trends in the study area?

3. Are the majority of the figures and tables focused on validating a proposed model, or are they examining trends, drivers, and impacts of inland water quality?

With regards to the third criterion, figures and tables within each paper were categorized into the four groups depending on whether they provided background information, model validation, or spatiotemporal analysis (details in Table S1). The final index (Appendix A) depicts a field of research that has evolved, particularly in the last decade, from almost universally methods-focused into one in which new methodologies, data products, and increased computing power are creating opportunities to address science questions related to water quality in novel ways.

The overall trend in the publication counts of the detailed dataset closely parallels the power-law trend in the broad Scopus query, including a comparable spike in publications after 2008 . Similarly, $75 \%$ of the

492 studies resulting from the various searches focus on lakes and lake related water quality parameters (Figure 
3). Eutrophication-associated parameters (chlorophyll, clarity, and cyanobacteria) are almost entirely measured in lake systems. In contrast, studies focusing on rivers, deltas, and estuaries are almost exclusively measuring sediment loading and transport parameters (TSS and turbidity).

In total, the included papers presented 411 models for constituent retrieval. Of these, only $70 \%$ reported some measure of goodness-of-fit or absolute error, and only $23 \%$ reported some measure of validation, with validation defined as an error metric derived from data not used in building the model. The most commonly reported metric was a coefficient of determination $\left(\mathrm{R}^{2}\right)$, with mean recorded values of

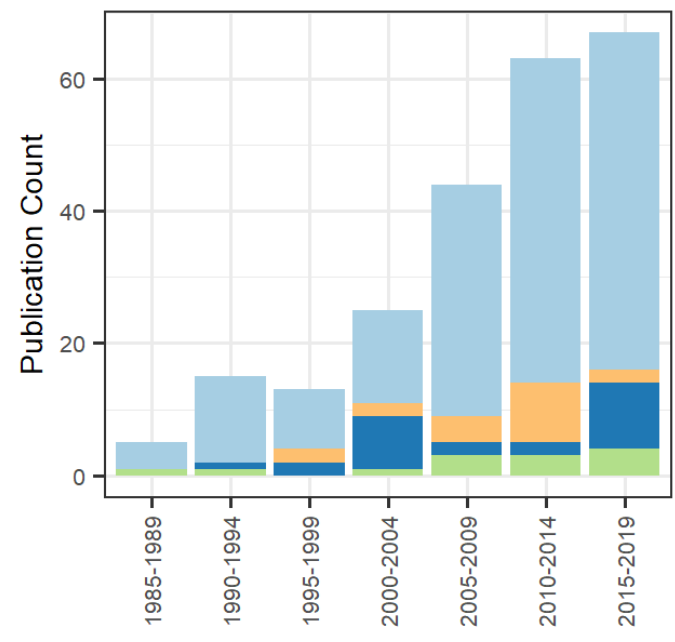

Time Period

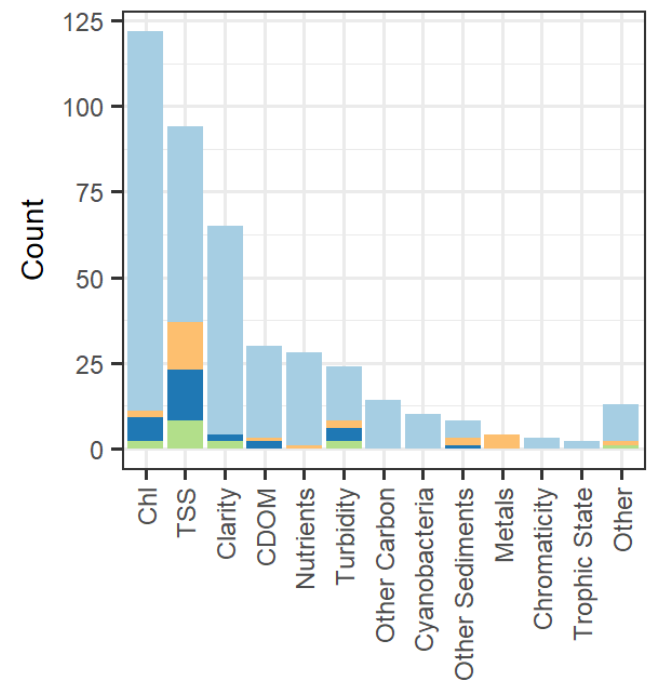

Parameter

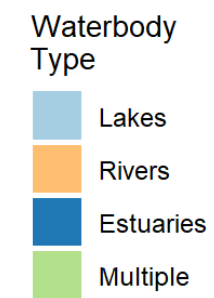

Figure 3. Publication counts within the detailed index binned by time and water quality parameter of interest. Colors represent type of waterbody being researched.

$0.76(\sigma=0.184)$ for model fit and $0.79(\sigma=0.159)$ for model validation (Figure 4). Simple linear regression of $\mathrm{R}^{2}$ values over time indicate that model fit has decreased $(p=0.011)$ and model validation has shown no significant trend $(p=0.633)$. However, more recent models frequently cover larger spatiotemporal domains and represent more difficult constituent retrieval, possibly leading to reduced model fit. While $\mathrm{R}^{2}$ values are not the most robust stand-alone metric of model performance [215], comparisons

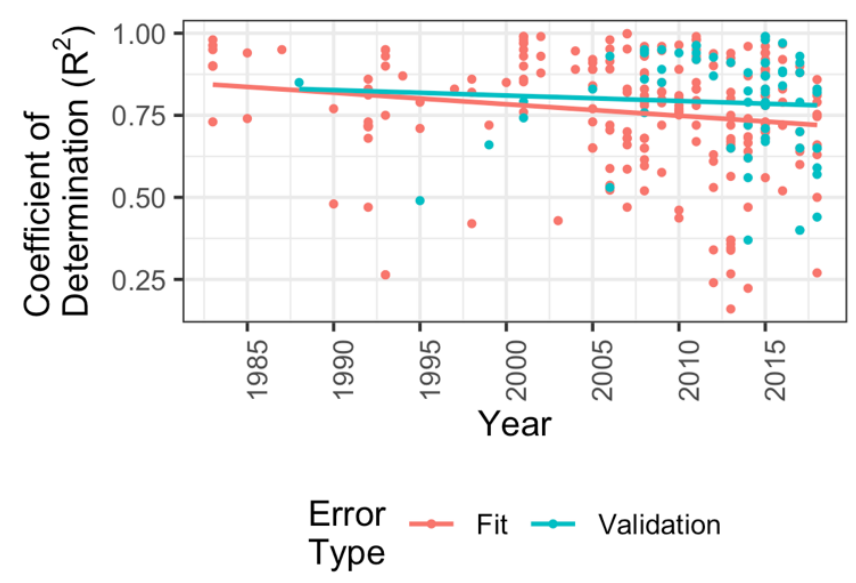

Figure 4. Reported $\mathrm{R}^{2}$ values for model fit and model validation along with linear regressions of $R^{2}$ over time. within the literature. Many of these represent differences in terminology as difficult due to the lack of standardization between reported metrics within the reviewed publications. In total, over 35 different error metrics were identified opposed to the actual statistical measure. For example, root mean square error (RMSE) is referred to nine different ways in total, with variations both in terminology (e.g. - root mean square error and root mean 
square deviation) and metric transformation (e.g. - percent, normalized, relative, and log values). Similar ranges of variation occur for mean/median absolute error (MAE), standard error (SE), relative error (RE), and bias. This disparity in reporting measures makes it difficult to accurately compare model error across studies without significant burden on the reader. However, examination of the most common metric, $\mathrm{R}^{2}$, suggests consistently strong model fits dating back to the 1970s (Figure 4). These results suggest that the potential has long existed for remote sensing to contribute to addressing scientific questions related to water quality. The reasons for the lag between methods development and scientific application remain uncertain. Two possible explanations are that the empirical models that dominate early literature were too site-specific to be useful at larger scales, or that perceptions of the usefulness of remote sensing in water quality research differed between the remote sensing community and fields like hydrology, limnology, and ecology.

Trends in modelling approach indicate a fairly static field up until the early 1990s, with empirical modelling approaches comprising $50-80 \%$ of all publications for nearly 20 years (Figure 5). The mid-2000s show an increase in publications employing machine learning models and pre-produced satellite products.

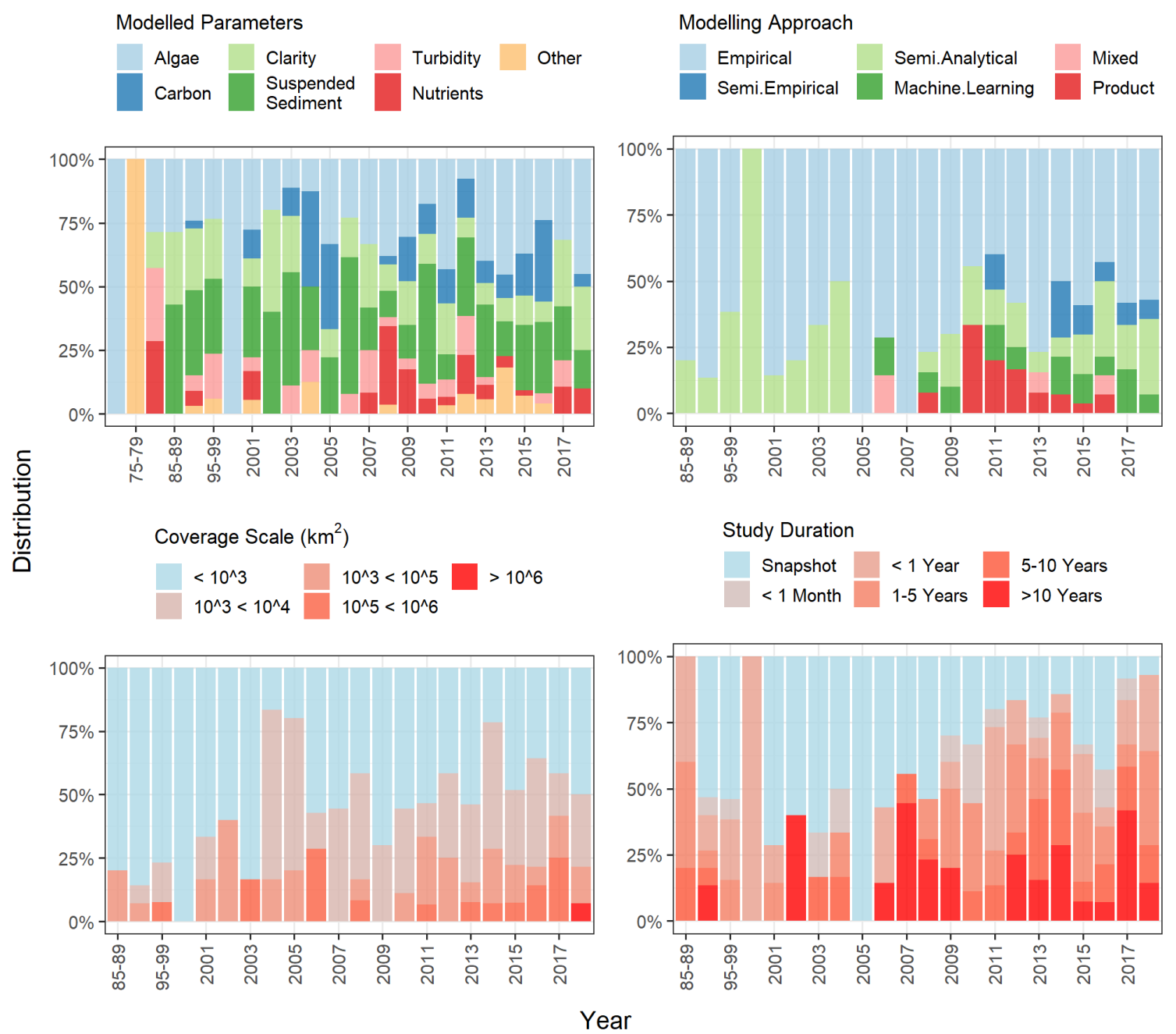

Figure 5. Temporal distributions of key study characteristics. Results for 1975-1999 are reported in fiveyear windows due to the relatively small number of studies published during this time period. 
launch of the Medium Resolution Imaging Spectrometer (MERIS) in 2002 and its decommission in 2012. MERIS presented a unique step towards global products through the development of the BEAM processing toolbox (Brockman Consult in collaboration with the European Space Agency), which utilizes a neural network scheme to simultaneously conduct atmospheric correction and water quality estimates. BEAM provided ready-made water quality products to inland water and ocean researchers alike, though validation of the products was regionally inconsistent [216-218].

The development of BEAM's neural network scheme and the rise in machine learning approaches starting around 2000 is likely attributable to increased computational capabilities and a proliferation of specialized software in common programming environments like $\mathrm{R}$ and Python. For the former, packages like Rpart [219], originally released in 1999, and nnet [220] created previously unavailable access to decision tree and neural network modelling approaches. For Python, software development throughout the 2000s led to comprehensive machine learning libraries such as Scikit-learn [221], which provided both access to common machine learning algorithms and a framework for their calibration and validation. These machine learning tools, among others, emerged in part due to an increased need for open source software that promoted study replicability, researcher access, and collaborative code development for machine learning researchers across fields [222].

The emergence of machine learning approaches in remote sensing of inland waters is paralleled by an increase in semi-empirical models. Initially, this late appearance of semi-empirical models appears unintuitive since they are computationally inexpensive and closely parallel older terrestrial indexes like NDVI; however, their emergence is likely explained by a proliferation of data from ocean color sensors such as SeaWiFs (launched 1997), MODIS Terra and Aqua (1999 and 2002 respectively), and MERIS (2002). With MERIS specifically, its high spectral resolution and chlorophyll-specific band centers allowed for better detection of absorption and backscattering peaks that facilitate semi-empirical models [88]. However, due to their coarse spatial resolution, these studies are mostly limited to larger lakes. These sensors were subsequently joined by the hyperspectral sensor Hyperion in 2000, which created new opportunities for semi-analytical water constituent retrieval [62].

Spatial examination of the literature reveals a dominance of studies located in the U.S., Europe, and China (Figure 6). China and the U.S., respectively, comprise 20 and $24 \%$ of the total studies included, with a notable clustering of long-term, large-scale studies in the Yangtze Basin. Spatiotemporal trends in publication dates depict a temporal expansion outward, with the earliest studies located almost exclusively in the U.S and subsequent publications spreading out across the globe. However, it should be noted that this trend may be partially attributable to a language bias in early publications where there is less access to non-English papers.

\section{From methods to applications: an overview of inland water remote sensing}

The study of water quality in lakes, rivers, and estuaries using remote sensing has expanded substantially over the past 50 years. When considering the intent of the publications as opposed to just the number, it is apparent that only in the past 10-15 years has inland water remote sensing consistently been used as a powerful analytical tool informing the broader inland water literature. In the papers reviewed for this analysis, twice as many studies were published in the past ten years as in the previous 28 years combined, a rate much faster than the growth of academic publishing as a whole. Of papers published since 2008 , nearly $30 \%$ focus on examining drivers and impacts of water quality, compared to only $7 \%$ for the period prior (Figure 7). 


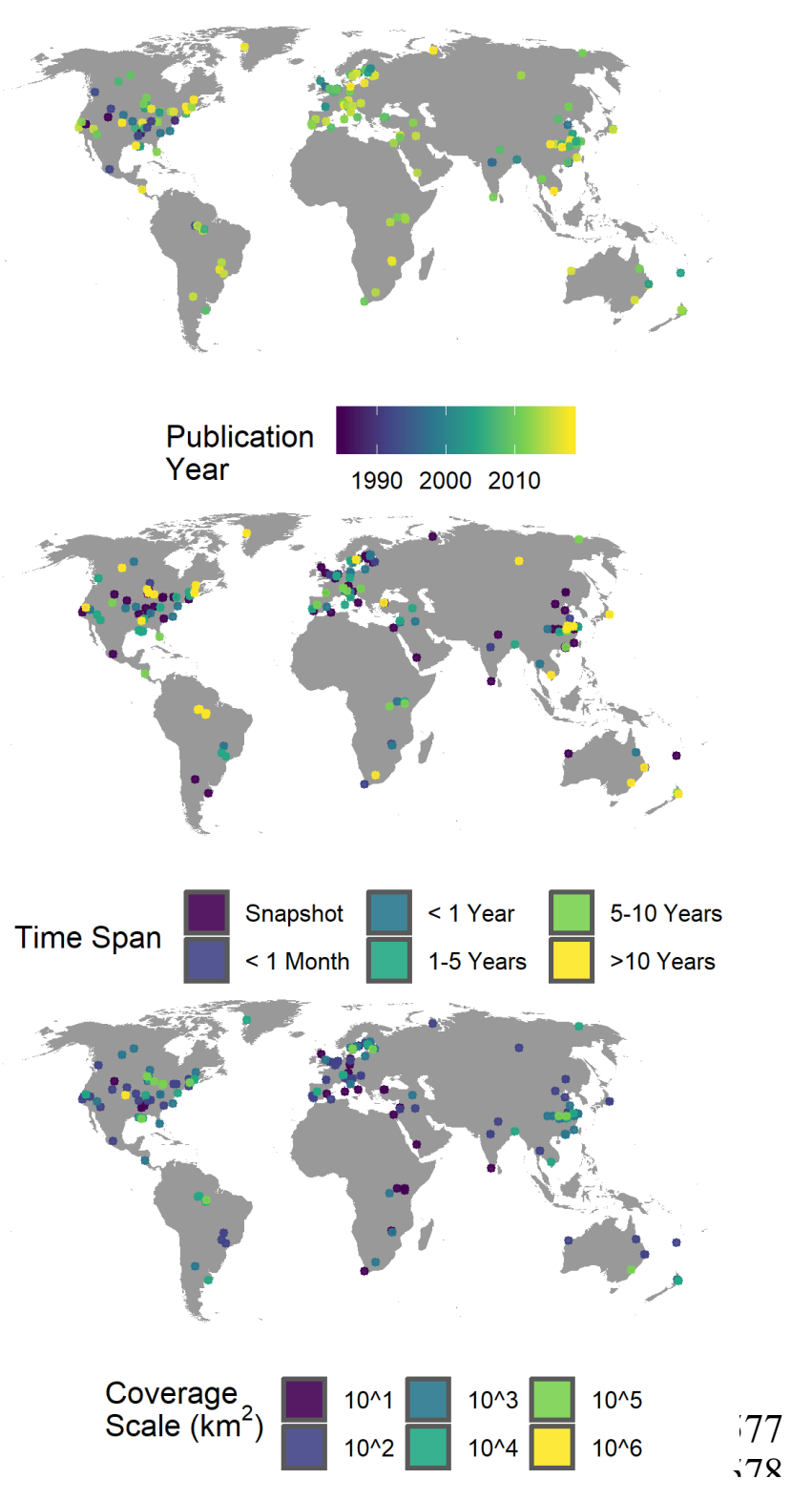

Figure 6. Spatial distribution of study publication date and scale
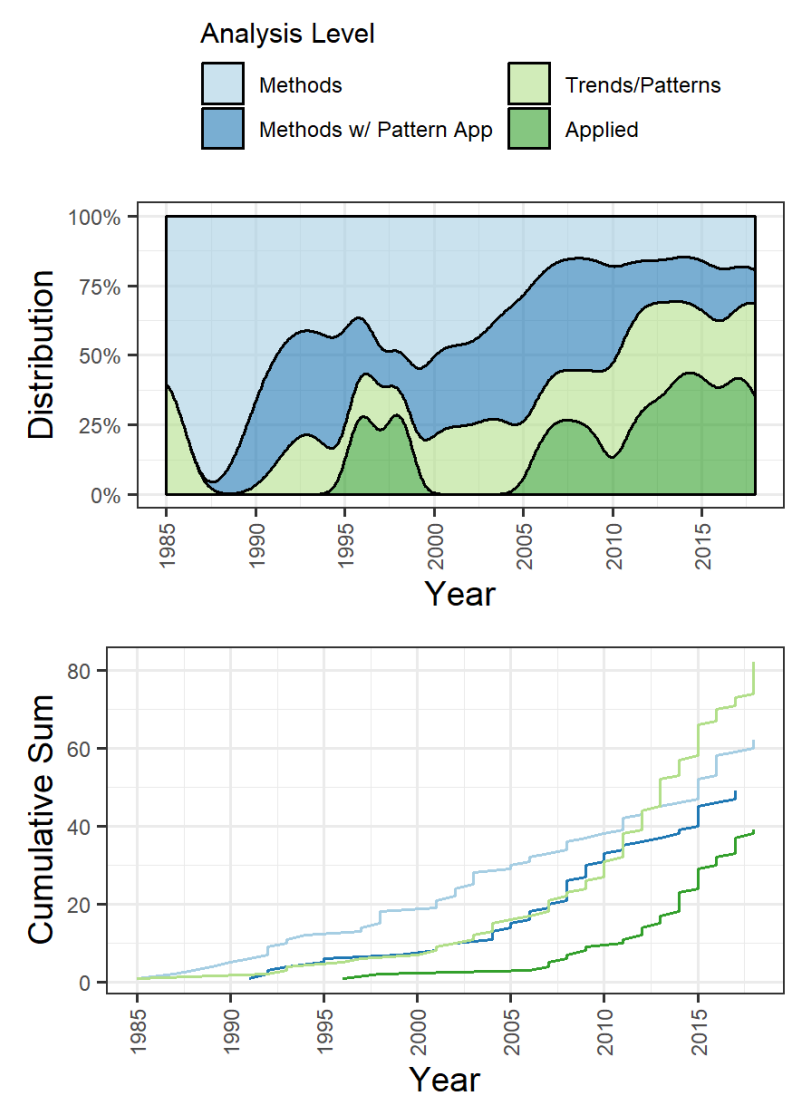

Figure 7: Progression of publication focus through time. Cumulative sum totals for methods categories ( $\mathrm{n}=113 ; 49 \%)$, trend/pattern papers $(\mathrm{n}=81 ; 35 \%)$, and water quality science papers ( $\mathrm{n}=38 ; 16 \%)$ show decreasing dominance of methods over time.

Studies are also expanding into longer timeframes and over larger spatial-scales (Figure 5). Pre-2008, the average study covered tens of square kilometers over a 2-year period. Post-2008, the average study examines hundreds of square

kilometers over a period of 5 years. This expansion requires the caveat that study scale is used as a proxy for the number of distinct lakes, and some of the increase in study scale may result from an increase in the average lake size rather than the total number of optically unique waterbodies. Similarly, longer term studies largely focus on simpler metrics such as water clarity and TSS, in part due to ongoing challenges modelling the more complex spectral signatures of chl-a and CDOM given the limited radiometric resolution of satellites like Landsat that provide longer time series of observations. Pearson's Correlation Coefficients [223] were calculated to identify relationships between study scale, duration, publishing date, and category. The category variable was converted to a numeric (1-4) in order of level of analysis (1, methods development; 2 , methods with pattern analysis; 3 , trend/pattern analysis; 4 , water quality science). other study parameters are still included to provide insight into how the scientific application of 
publications has changed with study scale and duration. The resulting correlation matrix (Table 2) depicts a clear pattern between study scale and impact over time. All four of the included variables were positively correlated at a $99 \%$ significance level (with the exception of study category and scale, $p=0.014$ ). While none of the correlations are particularly strong, their significance and consistency indicate that studies published later tend to cover larger spatiotemporal domains

600 and focus more on

601 analyzing water quality

602 dynamics and impacts

603 than on methods

604 development.

This shift in study focus, scale, and duration all Table 2. Correlation matrix of key study parameters. All correlation are significant at a $99 \%$ confidence interval $\left(^{* * *}\right)$. Study category rescaled to $1-4$ representing the four levels of analysis from purely methodological to water quality science papers. suggest that remote sensing

\begin{tabular}{|c|c|c|c|c|}
\hline \multirow{2}{*}{\begin{tabular}{c} 
Pub. Year \\
\cline { 2 - 5 }
\end{tabular}} & Pub. Year & \multicolumn{2}{c|}{ Study Duration } & \multicolumn{2}{c|}{ Study Scale } & Study Category \\
\cline { 2 - 5 } Study Duration & 1 & 0.171 & 0.255 & 0.342 \\
\cline { 2 - 5 } $\begin{array}{c}\text { Study Scale } \\
\text { Study Category }\end{array}$ & $* * *$ & 1 & 0.326 & 0.32 \\
\hline
\end{tabular}
is becoming a useful tool in understanding inland water quality rather than an area for methodological study among remote sensing specialists. Publications representative of this shift towards hypothesisdriven science vary significantly in their focus, with emphasis on hydrological processes, drivers of water quality, public hazard identification, and impacts of degraded water quality (Table S2).

Studies examining drivers of water quality at local to regional scales comprise the largest group of water quality science publications. Recent work has examined climatic, anthropogenic, and landscapescale variables that interact with complex biogeophysical water quality properties. Work by Lymburner et al. (2016)[175] presents a 30-year analysis of TSS in Australian lakes, showing distinct relationships between El Niño Southern Oscillations and fluctuations in TSS levels. Olmanson, Brezonik, \& Bauer (2014)[224], examined a 20-year record of remotely sensed water clarity for over 10,000 lakes in Minnesota. Their results showed significant differences in overall trends based on land use and eco-region. $\mathrm{Ng}$ et al. (2011)[225] and Curtarelli et al. (2015)[98] both incorporated remotely sensed chl-a data into hydrologic models and found that thermal stratification and mixing were key drivers of algal bloom growth and dispersion. Work done by Rose et al. (2017)[148] showed that controls on water clarity move from local to watershed scales during dry and wet years respectively. Other studies focusing on climatic drivers of water quality have used remote sensing to analyze the impacts of hurricanes [226], typhoons [227], and growing season length [228] on various water quality metrics.

Studies focusing on anthropogenic drivers have brought to light the impacts of human activities on freshwater resources for areas ranging from individual lakes to entire states. Work by Cui and others (2009, 2013)[229,230] examined the combined effects of precipitation, river flows, and dredging on TSS levels in Poyang Lake in China. They found that the combined precipitation and anthropogenic impacts degraded water quality far more than either individual driver could on its own. At a basin scale, Ren et al. (2018)[231] and Hou et al. (2017)[232] conducted studies examining how the Three Gorges Reservoir affected water clarity and TSS dynamics in the Yangtze Basin. In the Peace-Athabasca Delta, Pavelsky \& Smith (2009)[233] and Long \& Pavelsky (2013)[234] utilized multi-temporal images of sediment loads to calculate river velocity and recharge for floodplain lakes.

Studies using remote sensing of water quality to address scientific questions extend beyond the field of hydrology and into biology and public health. Sandström et al. (2016) [235] utilized remotely sensed CDOM and chl-a concentrations to analyze fish habitat assemblages and biodiversity. For public health, inland water remote sensing is helping to analyze disease distribution and drinking water hazards. Fichot 638 et al. (2016)[70] identified spatial patterns of methylmercury in the San Francisco Bay area using an airplane 
mounted hyperspectral sensor. Qin et al. (2015)[29] developed a dynamic forecasting model capable of predicting the presence of toxic algal blooms. The model ultimately resulted in over one million tons of algal scum being removed from a drinking water reservoir in China [29]. Other authors have similarly identified public threats to drinking water in Lake Mead (USA) [182] and Lake Chaohu in China [190]. Two specific studies stood out through their novel use of remote sensing to facilitate epidemiological studies. Torbick et al. (2014)[236] incorporated Landsat-derived water quality parameters into an ecoepidemiological model to examine the distribution of amyotrophic lateral sclerosis (ALS) across New England. They found that close proximity to waterbodies with elevated levels of nitrogen increased the odds of being located within an ALS hotspot by 167\%. Similarly, Finger et al. (2014)[237] incorporated remotely sensed chl-a measurements into a model of cholera dynamics within the Democratic Republic of Congo.

One additional subset of the reviewed literature merits discussion when considering advances in the field; specifically, researchers who are continuing to expand the spatiotemporal scale of their study areas. The need for global data products has received increasing attention in recent years as an essential aspect to protecting threatened freshwater resources [15-17]. Within the U.S., work towards this goal includes state-wide analyzes of Secchi Disk depth in Minnesota [157,224] and Maine [238], and a national approach to modelling lake chl-a [188]. Outside the U.S., previously mentioned work by Lymberner et al. (2016)[175] in Australian lakes and Hou et al. (2017)[232] in the Yangtze basin both cover areas of tens of thousands of square kilometers, albeit without including every lake in the study region.

Publications like those mentioned above are complemented by a host of living databases and interactive web services that are increasing access to near real-time water quality information. The Copernicus Inland Water Service provides semi-continuous (2002-2012, 2016-present) turbidity and chl-a observations for approximately 1,000 of the world's largest lakes (https://land.copernicus.eu/global/products/lwq). Similarly, the Minnesota LakeBrowser provides periodic measurements of chl-a, CDOM, and water clarity dating back to 2002 for over 10,000 lakes across the state (https://lakes.rs.umn.edu/). These publicly available databases are being supplemented by private companies like EOMAP (https://www.eomap.com/) which provide remotely sensed estimates of water quality parameters on a contract basis around the globe. While validation of some of these products is difficult to obtain, they are facilitating increased access to water quality data for water managers and researchers alike. Improvements in modeling methodologies and growing access to both in situ and earth observation data are setting the stage for future studies at larger and larger scales.

\section{Emerging Trends in the Remote Sensing of Water Quality}

The past decade has seen a dramatic growth in the resources necessary to remotely sense inland water quality. One example highlighted here is the 2008 shift to open access Landsat data, after which publication counts rose and study scale and duration increased significantly. However, the Landsat archive is only one of numerous petabyte-size archives of earth observation data provided by government agencies such as NASA, the USGS, NOAA, and the European Space Agency. These archives are constantly expanding and will continue to do so in the coming years. Starting in 2010, access to these data sources further increased with the release of the Google Earth Engine platform, which hosts imagery and resulting data products from over a dozen different earth observation sensors. The platform provides free access to these datasets along with cloud-based processing, dramatically increasing the computational power of remote sensing researchers across fields. For inland water remote sensing, Lin et al. (2018)[188] combined in situ data from the 2007 National Lake Assessment ( $=1157$ lakes) with Landsat data and machine learning algorithms built into Earth Engine to develop a well-validated national model for lake chl-a (RMSE $=34.9 \mu \mathrm{g} / \mathrm{L}$ ). Similarly, Overeem et al. (2017)[112] used Google Earth Engine to model 
sediment export from Greenland over 14 years. Today, the platform continues to grow and increase in usefulness, adding approximately 6,000 scenes daily from various active satellite missions, with a latency of approximately 24 hours [239]. The power of Google Earth Engine essentially provides researchers with supercomputing capabilities from their local machines, dramatically increasing the scales at which earth observation research can take place. Platforms like Earth Engine are complimented by an ever-growing body of processing and analysis software in common programming languages like R [240].

While the provision of open-access satellite imagery to researchers is essential to the progression of the field, it alone cannot account for the shift in research focus and scale outlined above. Paralleling the rise in remote sensing data availability over the past decade has been a rise in the in situ data available for model calibration and validation. In the past, the burden of collecting this data frequently fell on individual researchers, significantly limiting the amount of field data available. Recent databases provided by government agencies, NGOs, and researchers alike are providing a wealth of freely available in situ data that is easily accessible. At a global level, the GEMStat database maintained through the International Centre for Water Resources and Global Change, provides over 4 million observations of lakes, rivers, wetlands, and groundwater systems from 4,000 sites spread over 75 countries (https://gemstat.org/). In the U.S., The National Water Quality Portal (WQP), released in 2012 by the USGS, EPA, and National Water Quality Monitoring Network, provides national coverage of archived state, federal, and tribal water quality field measurements. In total it assimilates and standardizes monitoring data for over 2 million individual sampling sites [241]. The Lake Multi-Scaled Geospatial and Temporal Database (LAGOS-NE) provides a similar assimilation of in situ water quality measurements for 17 water-rich states in the upper Midwest and Northeast United States, providing historical field data for over 51,000 lakes and reservoirs [242]. These datasets have already been used as calibration and validation data for remote sensing of water skin temperature [243]. In Europe, national-scale water quality data for inland and coastal waters are compiled from participating agencies into the Waterbase dataset, which is harmonized and made research ready under the WISE system (water information system for Europe) [244]. These official data sources can be supplemented with novel collections aggregated through citizen science campaigns. These include Eye On Water (http://www.eyeonwater.org/) and Seen-monitoring (http://www.seentransparent.de/) in Europe, the Secchi-Dip In in North America (http://www.secchidipin.org/), and state level efforts in Minnesota, Wisconsin, Michigan, and Maine (https://www.pca.state.mn.us/water/citizenwater-monitoring, $\quad$ https://www.uwsp.edu/cnr-ap/UWEXLakes/Pages/programs/clmn/default.aspx, https://micorps.net/lake-monitoring/, and https://www.lakestewardsofmaine.org/ respectively). Together these campaigns have collected hundreds of thousands of observations available to researchers. The new AquaSat database from Ross et al. (in review)[245] uses Google Earth Engine to extract coincident (+/- 1 day) Landsat reflectance values for in situ measurements found in the WQP and LAGOS-NE. The result is the first dataset of its kind, providing over 500,000 paired observations of reflectance values and associated water quality parameters in optically complex waters dating back to 1984 . Databases such as these provide data continuity, cost and time savings for researchers, and large calibration and validation samples for model development.

The development and expansion of new and existing databases is paralleled by the development of new sensor technology. Airborne hyperspectral sensors capable of capturing contiguous spectral signatures of water-leaving radiance have provided new levels of precision to measure optically active constituents (see reviews by $[3,60]$ ). These airborne campaigns are working towards satellite missions such as NASA's Surface Biology and Geology mission (SBG, in development), Italy's PRecursore IperSpettrale della Missione Applicativa (PRISMA, launched March 22, 2019), Japan's Hyperspectral Imaging Suite (HISUI, planned 2019), and Germany's Environmental Mapping and Analysis Program (EnMAP, planned 2020) [246]. These spaceborne imaging spectrometers will increase spatiotemporal transferability of retrieval models, improve overall constituent retrieval, facilitate biogeochemical 
composition analysis, enable benthic habitat identification in optically shallow water bodies, and allow for the retrieval of additional detectable water quality parameters that are currently unfeasible with broadband, multispectral sensors, all while providing global hyperspectral data at roughly 30 meter resolution [17,18]. Traditional governmental satellite missions are being supplemented with a host of novel earth observation technologies being developed by commercial companies such as Planet (https://www.planet.com/), MAXAR (https://www.maxar.com/), and Airbus (https://www.airbus.com/). These private platforms are creating novel opportunities for hydrological remote sensing through public and academic research partnerships. For example, Planet, which operates over 150 small imaging satellites that provide daily global imagery at 3-5 meter resolution, collaborated with Cooley et al. (2017)[247] to study lake connectivity in the Yukon Flats region of Alaska at previously unfeasible spatial scales. For inland water quality, the high spatial and temporal resolution of such satellite constellations will allow for detection of short-term phenomena like algal blooms in streams and lakes that are currently too small to study with publicly available satellite imagery. These efforts to improve research in small aquatic systems are being further aided by the increased use of unmanned aerial vehicles and even smartphones [248].

These emerging technologies will allow the inland water quality remote sensing community to overcome historic challenges and examine new science questions. However, this process will require dedicated researchers and reliable funding sources. While emerging technologies hold promise, they also present new challenges. Hyperion, the first spaceborne hyperspectral sensor believed to be appropriate for inland waters, showed initial promise [62] but ultimately proved unreliable over waterbodies due to its low signal to noise ratio and radiometric instability [249]. The Planet constellation of CubeSats, while providing unprecedented spatial and temporal resolution, are subject to geolocation accuracy errors and inconsistencies in radiometric calibration between satellites [247]. These issues are in addition to wellcharacterized challenges including robust atmospheric correction and solving adjacency effects, both of which need to be applied across sensors to create comparable datasets. Solutions to these existing challenges will likely be developed through improvements in sensor engineering, computational capacity, and modelling approaches, as well as growing collaborative efforts by international groups such as IOCCG $[20,250]$ and the Committee on Earth Observation Satellites [56]. As existing issues are overcome, remote sensing of inland water quality can be applied to address relevant scientific questions and conservation goals, including those outlined in the NRC Decadal Survey [251] and the EU Water Framework Directive [252]. Conducting such research will help solve water quality issues of global importance and better inform water managers, policy makers, and the scientific community regarding critical science questions. Some of the most pressing questions synthesized from the reviewed literature include:

- How does biogeochemical cycling of suspended sediments and CDOM in lakes and rivers contribute to the global carbon cycle?

- How are added nutrient inputs and warming air temperatures contributing to the frequency and distribution of harmful algal blooms in lakes and reservoirs?

- What is the impact of anthropogenic development, including urbanization and reservoir construction, on basin-wide water quality?

- What are the patterns and trends in the biogeochemistry of water resources in remote, vulnerable areas including the Arctic and Boreal regions?

- How are changes in water quality affecting the biological structure of freshwater resources at regional to global scales?

- How are changing water quality dynamics impacting important drinking water resources? 


\section{Conclusion}

The bibliometric analysis presented here highlights the dramatic growth of inland water quality remote sensing studies, far outpacing the average rate of increase in academic publishing as a whole. The past 50 years have produced hundreds of remote sensing publications accurately estimating biogeochemical water quality parameters; however, the majority of these focus on methods development rather than using remote sensing as a tool to better understand inland water quality dynamics. Detailed examination of 236 of the most relevant publications returned by search queries indicates that the past 1015 years has brought about a focal shift within the field, where researchers are moving beyond methods development towards research focused on spatiotemporally explicit water quality dynamics. This shift is partially attributable to the development of new satellite and in situ datasets, improved access to satellite imagery, and increased computational/software capabilities. The current change in focus within the field is similar in nature to the shift that occurred in ocean color and terrestrial remote sensing throughout the 1980s and 1990s, after which time both fields applied remote sensing to answer some of the most pressing science questions of their time. For inland water quality, the progression of research is evidenced by a subset of recent publications which have begun to leverage remote sensing to examine water quality trends, ecological and anthropogenic drivers, and resulting impacts of changing water quality on ecosystem function and water resources. This shift has been accompanied by a significant increase in the spatiotemporal scale of analysis, moving the field closer to providing national to global-scale data products for policy makers, water managers, and scientists. The increase in high quality science and study scale within the field continues to be facilitated by improved data-sets and growing computational capacity. New data products like AquaSat [245] promise to continue this trajectory of growth and facilitate a new generation of inland water remote sensing research.

Based on the literature reviewed here, future inland water quality remote sensing work will benefit greatly from the following recommendations: 1) continued development of generalizable constituent retrieval models, including atmospheric corrections, that are applicable across large spatiotemporal domains and across differing sensors; 2 ) the expanded application of robust, generalizable models to better understand global processes including erosion and deposition, terrestrial carbon and nutrient cycling, and trends in algal bloom dynamics in inland waters ; 3) improved communication between experts in remote sensing and scientists in fields such as hydrology, limnology, and ecology, in order to facilitate the wider adoption of remote sensing models in scientific studies of water quality; and, 4) the development of userfriendly tools that inform local water managers of remotely sensed changes in water quality to promote sound policy and the conservation of essential freshwater resources. 


\section{References}

808 1. Wrigley, R.C.; Horne, A.J. Remote sensing and lake eutrophication. Nature 1974, 250, $213-214$.

809 2. Scarpace, F.; Holmquist, K.; Fisher, L. Landsat analysis of lake quality. Photogramm. Eng. Remote Sensing 1979, $810 \quad 45,623-633$.

$8113 . \quad$ Gholizadeh, M.; Melesse, A.; Reddi, L. A Comprehensive Review on Water Quality Parameters Estimation $812 \quad$ Using Remote Sensing Techniques. Sensors 2016, 16, 1298.

813 4. Matthews, M.W. A current review of empirical procedures of remote sensing in Inland and near-coastal transitional waters. Int. J. Remote Sens. 2011, 32, 6855-6899.

5. Odermatt, D.; Gitelson, A.; Brando, V.E.; Schaepman, M. Review of constituent retrieval in optically deep and complex waters from satellite imagery. Remote Sens. Environ. 2012, 118, 116-126.

819 7. Tucker, C.J. Red and photographic infrared linear combinations for monitoring vegetation. Remote Sens. Environ.

6. Liu, Y.S.; Islam, M.A.; Gao, J. Quantification of shallow water quality parameters by means of remote sensing . Prog. Phys. Geogr. 2003, 27, 24-43. 1979, 8, 127-150.

8. Matthews, E. Global Vegetation and Land Use: New High-Resolution Data Bases for Climate Studies. J. Clim. Appl. Meteorol. 1983, 22, 474-487.

9. Tarpley, J.D.; Schneider, S.R.; Money, R.L. Global Vegetation Indices from the NOAA-7 Meteorological Satellite. J. Clim. Appl. Meterology 1984, 23, 491-494.

10. Box, E.O.; Holben, B.N.; Kalb, V. Accuracy of the AVHRR vegetation index as a predictor of biomass, primary productivity and net CO2 flux. Vegetatio 1989, 80, 71-89.

11. Tucker, C.J.; Fung, I.Y.; Keeling, C.D.; Gammon, R.H. Relationship between atmospheric CO2 variations and a satellite-derived vegetation index. Nature 1986, 319, 195-199.

12. Feldman, G.; Kuring, N.; Ng, C.; Esaias, W.; McClain, C.; Elrod, J.; Maynard, N.; Endres, D.; Evans, R.; Brown, J.; et al. Ocean color: Availability of the global data set. Eos, Trans. Am. Geophys. Union 1989, 70, 634.

13. Platt, T.; Sathyendranath, S. Oceanic Remote Primary Production: Estimation by Remote Sensing at Local and Regional Scales. Science (80-. ). 1988, 241, 1613-1620.

14. Zandaryaa, S. The UNESCO-IHP IIWQ World Water Quality Portal - Whitepaper -; 2018;

15. Lee, B.Z.; Arnone, R.; Boyce, D.; Franz, B.; Greb, S.; Hu, C.; Lewis, M.; Schaeffer, B.; Shang, S.; Wang, M.; et al. Global Water Clarity : Continuing a Century-Long Monitoring. Eos (Washington. DC). 2018, 99, 1-10.

16. Malthus, T.J.; Hestir, E.L.; Dekker, A.G.; Brando, V.E. The case for a global inland water quality product. IEEE IGARSS 2012, 5234-5237.

17. Hestir, E.L.; Brando, V.E.; Bresciani, M.; Giardino, C.; Matta, E.; Villa, P.; Dekker, A.G. Measuring freshwater aquatic ecosystems: The need for a hyperspectral global mapping satellite mission. Remote Sens. Environ. 2015, $167,181-195$.

18. Giardino, C.; Brando, V.E.; Gege, P.; Pinnel, N.; Hochberg, E.; Knaeps, E.; Reusen, I.; Doerffer, R.; Bresciani, M.; Braga, F.; et al. Imaging Spectrometry of Inland and Coastal Waters: State of the Art, Achievements and Perspectives. Surv. Geophys. 2019, 40, 401-429.

19. Tyler, A.N.; Hunter, P.D.; Spyrakos, E.; Groom, S.; Constantinescu, A.M.; Kitchen, J. Developments in Earth observation for the assessment and monitoring of inland, transitional, coastal and shelf-sea waters. Sci. Total Environ. 2016, 572, 1307-1321.

20. IOCCG. Earth Observations in Support of Global Water Quality Monitoring. Greb, S., Dekker, A. and Binding, C. (eds.), IOCCG Report Series, No. 17, International Ocean Colour Coordinating Group, Dartmouth, Canada, 2018;

21. Bukata, R.P.; Bruton, J.E.; Jerome, J.H.; Jain, S.C.; Zwick, H.H. Optical water quality model of Lake Ontario 2: Determination of chlorophyll a and suspended mineral concentrations of natural waters from submersible and low altitude optical sensors. Appl. Opt. 1981, 20, 1704.

22. Bukata, R.P.; Jerome, J.H.; Bruton, J.E. Particulate concentrations in Lake St. Clair as recorded by a shipborne multispectral optical monitoring system. Remote Sens. Environ. 1988, 25, 201-229.

23. Dekker, A.G.; Seyhan, E. The remote sensing loosdrecht lakes project. Int. J. Remote Sens. 1988, 9, 1761-1773.

24. Kirk, J.T.O.; Tyler, P.A. The spectral absorption and scattering properties of dissolved and particulate components in relation to the underwater light field of some tropical Australian fresh waters. Freshw. Biol. 1986, 
858
$16,573-583$.

25. Kishino, M.; Booth, C.R.; Okami, N. Underwater radiant energy absorbed by phytoplankton, detritus, dissolved organic matter, and pure water. Limnol. Oceanogr. 1984, 29, 340-349.

26. Seyhan, E.; Dekker, A. Application of Remote Sensing Techniques for Water Quality Monitoring. Hydrobiol. Bull. 1986, 20, 41-50.

27. Stumpf, R.P.; Pennock, J.R. Calibration of a general optical equation for remote sensing of suspended sediments in a moderately turbid estuary. J. Geophys. Res. 1989, 94, 14363.

28. Walker, N.D. Satellite assessment of Mississippi River plume variability: Causes andpredictability. Remote Sens. Environ. 1996, 58, 21-35.

29. Qin, B.; Li, W.; Zhu, G.; Zhang, Y.; Wu, T.; Gao, G. Cyanobacterial bloom management through integrated monitoring and forecasting in large shallow eutrophic Lake Taihu (China). J. Hazard. Mater. 2015, $287,356-363$.

30. Falcini, F.; Khan, N.S.; Macelloni, L.; Horton, B.P.; Lutken, C.B.; Mckee, K.L.; Santoleri, R.; Colella, S.; Li, C.; Volpe, G.; et al. Linking the historic 2011 Mississippi River flood to coastal wetland sedimentation. Nat. Geosci. 2012, 5, 803-807.

31. Miller, R.L.; McKee, B.A. Using MODIS Terra $250 \mathrm{~m}$ imagery to map concentrations of total suspended matter in coastal waters. Remote Sens. Environ. 2004, 93, 259-266.

32. Adamo, M.; Matta, E.; Bresciani, M.; Carolis, G. De; Vaiciute, D.; Giardino, C.; Pasquariello, G. On the synergistic use of SAR and optical imagery to monitor cyanobacteria blooms: The Curonian Lagoon case study. Eur. J. Remote Sens. 2013, 46, 789-805.

33. Matthews, M.W.; Bernard, S.; Winter, K. Remote sensing of cyanobacteria-dominant algal blooms and water quality parameters in Zeekoevlei, a small hypertrophic lake, using MERIS. Remote Sens. Environ. 2010, 114, 20702087.

34. Palmer, S.C.J.; Odermatt, D.; Hunter, P.D.; Brockmann, C.; Présing, M.; Balzter, H.; Tóth, V.R. Satellite remote sensing of phytoplankton phenology in Lake Balaton using 10years of MERIS observations. Remote Sens. Environ. 2015, 158, 441-452.

35. Bresciani, M.; Stroppiana, D.; Odermatt, D.; Morabito, G.; Giardino, C. Assessing remotely sensed chlorophylla for the implementation of the Water Framework Directive in European perialpine lakes. Sci. Total Environ. 2011, 409, 3083-3091.

36. Bresciani, M.; Vascellari, M.; Giardino, C.; Matta, E. Remote sensing supports the definition of the water quality status of Lake Omodeo (Italy). Eur. J. Remote Sens. 2012, 45, 349-360.

37. Shen, M.; Duan, H.; Cao, Z.; Xue, K.; Loiselle, S.; Yesou, H. Determination of the downwelling diffuse attenuation coefficient of lakewater with the sentinel-3A OLCI. Remote Sens. 2017, 9.

38. Ritchie, J.C.; Cooper, C.M.; Schiebe, F.R. The relationship of MSS and TM digital data with suspended sediments, chlorophyll, and temperature in Moon Lake, Mississippi. Remote Sens. Environ. 1990, 33, 137-148.

39. Kloiber, S.M.; Brezonik, P.L.; Bauer, M.E. Application of Landsat imagery to regional-scale assessments of lake clarity. Water Res. 2002, 36, 4330-4340.

40. Mertes, L.A.K.; Smith, M.O.; Adams, J.B. Estimating suspended sediment concentrations in surface waters of the Amazon River wetlands from Landsat images. Remote Sens. Environ. 1993, 43, 281-301.

41. Wang, Y.; Xia, H.; Fu, J.; Sheng, G. Water quality change in reservoirs of Shenzhen, China: detection using LANDSAT/TM data. Sci. Total Environ. 2004, 328, 195-206.

42. Dekker, A.G.; Peters, S.W.M. The use of the thematic mapper for the analysis of eutrophic lakes: A case study in the netherlands. Int. J. Remote Sens. 1993, 14, 799-821.

43. Yacobi, Y.Z.; Gitelson, A.; Mayo, M. Remote sensing of chlorophyll in Lake Kinneret using high spectral resolution radiometer and Landsat Thematic Mapper Spectral features of reflectance and algorithm development. J. Plankton Res. 1995, 17, 2155-2173.

44. Ouillon, S.; Douillet, P.; Andréfouët, S. Coupling satellite data with in situ measurements and numerical modeling to study fine suspended-sediment transport: A study for the lagoon of New Caledonia. Coral Reefs 2004, 23, 109-122.

45. Tyler, A.N.; Svab, E.; Preston, T.; Présing, M.; Kovács, W.A. Remote sensing of the water quality of shallow lakes: A mixture modelling approach to quantifying phytoplankton in water characterized by high-suspended sediment. Int. J. Remote Sens. 2006, 27, 1521-1537.

46. Duan, H.; Zhang, Y.; Zhang, B.; Song, K.; Wang, Z. Assessment of chlorophyll-a concentration and trophic state for lake chagan using landsat TM and field spectral data. Environ. Monit. Assess. 2007, 129, 295-308. 
911

912

913

914

915

916

917

918

919

920

921

922

923

924

925

926

927

928

929

930

931

932

933

934

935

936

937

938

939

940

941

942

943

944

945

946

947

948

949

950

951

952

953

954

955

956

957

958

959

960

961

962

963
47. Watanabe, F.S.Y.; Alcântara, E.; Rodrigues, T.W.P.; Imai, N.N.; Barbosa, C.C.F.; Rotta, L.H. da S. Estimation of chlorophyll-a concentration and the trophic state of the barra bonita hydroelectric reservoir using OLI/landsat8 images. Int. J. Environ. Res. Public Health 2015, 12, 10391-10417.

48. Lee, Z.; Shang, S.; Qi, L.; Yan, J.; Lin, G. A semi-analytical scheme to estimate Secchi-disk depth from Landsat-8 measurements. Remote Sens. Environ. 2016, 177, 101-106.

49. Toming, K.; Kutser, T.; Laas, A.; Sepp, M.; Paavel, B.; Nõges, T. First experiences in mapping lakewater quality parameters with sentinel-2 MSI imagery. Remote Sens. 2016, 8, 1-14.

50. Kutser, T.; Paavel, B.; Verpoorter, C.; Ligi, M.; Soomets, T.; Toming, K.; Casal, G. Remote sensing of black lakes and using $810 \mathrm{~nm}$ reflectance peak for retrieving water quality parameters of optically complex waters. Remote Sens. 2016, 8 .

51. Doxaran, D.; Froidefond, J.M.; Lavender, S.; Castaing, P. Spectral signature of highly turbid waters: Application with SPOT data to quantify suspended particulate matter concentrations. Remote Sens. Environ. 2002, 81, 149161.

52. Dvornikov, Y.; Leibman, M.; Heim, B.; Bartsch, A.; Herzschuh, U.; Skorospekhova, T.; Fedorova, I.; Khomutov, A.; Widhalm, B.; Gubarkov, A.; et al. Terrestrial CDOM in lakes of Yamal Peninsula: Connection to lake and lake catchment properties. Remote Sens. 2018, 10, 1-21.

53. Hellweger, F.L.; Miller, W.; Oshodi, K.S. Mapping turbidity in the Charles River, Boston using a high-resolution satellite. Environ. Monit. Assess. 2007, 132, 311-320.

54. Sawaya, K.; Olmanson, L.G.; Heinert, N.; Brezonik, P.; Bauer, M. Extending satellite remote sensing to local scales: land and water resource monitoring using high-resolution imagery. Remote Sens. Environ. 2003, 88, 144156.

55. Olmanson, L.G.; Brezonik, P.L.; Bauer, M.E. Evaluation of medium to low resolution satellite imagery for regional lake water quality assessments. Water Resour. Res. 2011, 47, 1-14.

56. CEOS Feasibility Study for an Aquatic Ecosystem Earth Observing System; Dekker, A.G., Pinnel, N., Eds.; 2018;

57. Buiteveld, H.; Hakvoort, J.H.M.; Donze, M. Optical properties of pure water. In Proceedings of the Proceedings of SPIE 2258; Jaffe, J.S., Ed.; 1994; pp. 174-183.

58. Röttgers, R.; McKee, D.; Utschig, C. Temperature and salinity correction coefficients for light absorption by water in the visible to infrared spectral region. Opt. Express 2014, 22, 25093.

59. IOCCG. Remote Sensing of Ocean Colour in Coastal, and Other Optically-Complex, Waters. Sathyendranath, S. (ed.), Reports of the International Ocean-Colour Coordinating Group, No. 3, 2000;

60. Govender, M.; Chetty, K.; Bulcock, H. A review of hyperspectral remote sensing and its application in vegetation and water resource studies. Water SA 2007, 33, 145-151.

61. Bioucas-dias, J.M.; Plaza, A.; Camps-valls, G.; Scheunders, P.; Nasrabadi, N.M.; Chanussot, J. Hyperspectral Remote Sensing Data Analysis and Future Challenges. IEEE Geosci. Remote Sens. Mag. 2013, 6-36.

62. Brando, V.E.; Dekker, A.G. Satellite hyperspectral remote sensing for estimating estuarine and coastal water quality. IEEE Trans. Geosci. Remote Sens. 2003, 41, 1378-1387.

63. Fang, L.; Chen, S.; Li, H.; Gu, C. Monitoring water constituents and salinity variations of saltwater using EO-1 Hyperion satellite imagery in the Pearl River Estuary, China. In Proceedings of the IGARSS 2008 - 2008 IEEE International Geoscience and Remote Sensing Symposium; IEEE, 2008; Vol. 1, pp. I-438-I-441.

64. Hunter, P.D.; Tyler, A.N.; Willby, N.J.; Gilvear, D.J. The spatial dynamics of vertical migration by Microcystis aeruginosa in a eutrophic shallow lake: A case study using high spatial resolution time-series airborne remote sensing. Limnol. Oceanogr. 2008, 53, 2391-2406.

65. Wass, P.D.; Marks, S.D.; Finch, J.W.; Leeks, G.J.L.; Ingram, J.K. Monitoring and preliminary interpretation of inriver turbidity and remote sensed imagery for suspended sediment transport studies in the Humber catchment. Sci. Total Environ. 1997, 194-195, 263-283.

66. Knaeps, E.; Ruddick, K.G.; Doxaran, D.; Dogliotti, A.I.; Nechad, B.; Raymaekers, D.; Sterckx, S. A SWIR based algorithm to retrieve total suspended matter in extremely turbid waters. Remote Sens. Environ. 2015, 168, 66-79.

67. Choe, E.; van der Meer, F.; van Ruitenbeek, F.; van der Werff, H.; de Smeth, B.; Kim, K.W. Mapping of heavy metal pollution in stream sediments using combined geochemistry, field spectroscopy, and hyperspectral remote sensing: A case study of the Rodalquilar mining area, SE Spain. Remote Sens. Environ. 2008, 112, 32223233.

68. Palacios, S.L.; Kudela, R.M.; Guild, L.S.; Negrey, K.H.; Torres-Perez, J.; Broughton, J. Remote sensing of phytoplankton functional types in the coastal ocean from the HyspIRI Preparatory Flight Campaign. Remote 
1006

1007

1008

1009

1010

1011

1012

1013

1014

1015

1016

Sens. Environ. 2015, 167, 269-280.

69. Jensen, D.; Simard, M.; Cavanaugh, K.; Sheng, Y.; Fichot, C.G.; Pavelsky, T.; Twilley, R. Improving the Transferability of Suspended Solid Estimation in Wetland and Deltaic Waters with an Empirical Hyperspectral Approach.

70. Fichot, C.G.; Downing, B.D.; Bergamaschi, B.A.; Windham-Myers, L.; Marvin-Dipasquale, M.; Thompson, D.R.; Gierach, M.M. High-Resolution Remote Sensing of Water Quality in the San Francisco Bay-Delta Estuary. Environ. Sci. Technol. 2015, 50, 573-583.

71. Mobley, C.D. Ligth and Water: Radiative Transfer in Natural Waters. Ligth Water Radiat. Transf. Nat. Waters 1994, 592.

72. Morel, A.Y.; Gordon, H.R. Report of the working group on water color. Boundary-Layer Meteorol. 1980, 18, 343355 .

73. McCullough, I.M.; Loftin, C.S.; Sader, S.A. Combining lake and watershed characteristics with Landsat TM data for remote estimation of regional lake clarity. Remote Sens. Environ. 2012, 123, 109-115.

74. Torbick, N.; Hession, S.; Hagen, S.; Wiangwang, N.; Becker, B.; Qi, J. Mapping inland lake water quality across the Lower Peninsula of Michigan using Landsat TM imagery. Int. J. Remote Sens. 2013, 34, 7607-7624.

75. Lillesand, T.M.; Johnson, W.L.; Deuell, R.L. Use of landsat data to predict the trophic state of Minnesota lakes. Photogramm. Eng. Remote Sensing 1983, 49, 219-229.

76. He, W.; Chen, S.; Liu, X.; Chen, J. Water quality monitoring in a slightly-polluted inland water body through remote sensing - Case study of the Guanting Reservoir in Beijing, China. Front. Environ. Sci. Eng. China 2008, 2, 163-171.

77. Choe, E.; van der Meer, F.; van Ruitenbeek, F.; van der Werff, H.; de Smeth, B.; Kim, K.W. Mapping of heavy metal pollution in stream sediments using combined geochemistry, field spectroscopy, and hyperspectral remote sensing: A case study of the Rodalquilar mining area, SE Spain. Remote Sens. Environ. 2008, 112, 32223233.

78. Baban, S.M.J. Detecting water quality parameters in the norfolk broads, U.K., using landsat imagery. Int. J. Remote Sens. 1993, 14, 1247-1267.

79. Kutser, T. Passive optical remote sensing of cyanobacteria and other intense phytoplankton blooms in coastal and inland waters. Int. J. Remote Sens. 2009, 30, 4401-4425.

80. McCormick, P. V.; Cairns, J. Algae as indicators of environmental change. J. Appl. Phycol. 1994, 6, 509-526.

81. Carvalho, L.; Poikane, S.; Lyche Solheim, A.; Phillips, G.; Borics, G.; Catalan, J.; De Hoyos, C.; Drakare, S.; Dudley, B.J.; Järvinen, M.; et al. Strength and uncertainty of phytoplankton metrics for assessing eutrophication impacts in lakes. Hydrobiologia 2013, 704, 127-140.

82. Svirčev, Z.; Simeunović, J.; Subakov-Simić, G.; Krstić, S.; Pantelić, D.; Dulić, T. Cyanobacterial blooms and their toxicity in Vojvodina Lakes, Serbia. Int. J. Environ. Res. 2013, 7, 745-758.

83. Paerl, H.W.W.; Huisman, J. Climate change: A catalyst for global expansion of harmful cyanobacterial blooms. Environ. Microbiol. Rep. 2009, 1, 27-37.

84. Zhou, B.; Shang, M.; Wang, G.; Zhang, S.; Feng, L.; Liu, X.; Wu, L.; Shan, K. Distinguishing two phenotypes of blooms using the normalised difference peak-valley index (NDPI) and Cyano-Chlorophyta index (CCI). Sci. Total Environ. 2018, 628-629, 848-857.

85. Dierssen, H.M.; Kudela, R.M.; Ryan, J.P. Red and Black Tides : Quantitative Analysis of Water-Leaving Radiance and Perceived Color for Phytoplankton, Colored Dissolved Organic Matter, and Suspended Sediments Author ( s ): Heidi M . Dierssen, Raphael M . Kudela, John P. Ryan and Richard C . Limnol. Oceanogr. 2006, 51, 26462659.

86. Gitelson, A.; Mayo, M.; Yacobi, Y.Z.; Parparov, A.; Berman, T. The use of high-spectral-resolution radiometer data for detection of low chlorophyll concentrations in Lake Kinneret. J. Plankton Res. 1994, 16, 993-1002.

87. Gower, J.F.R.; Brown, L.; Borstad, G.A. Observation of chlorophyll fluorescence in west coast waters of canada using the MODIS satellite sensor. Can. J. Remote Sens. 2004, 30, 17-25.

88. Gower, J.F.R.; Doerffer, R.; Borstad, G.A. Interpretation of the $685 \mathrm{~nm}$ peak in water-leaving radiance spectra in terms of fluorescence, absorption and scattering, and its observation by MERIS. Int. J. Remote Sens. 1999, 20, 1771-1786.

89. Matthews, M.W.; Bernard, S.; Robertson, L. An algorithm for detecting trophic status (chlorophyll-a), cyanobacterial-dominance, surface scums and floating vegetation in inland and coastal waters. Remote Sens. Environ. 2012, 124, 637-652. 
1017

1018

1019

1020

1021

1022

1023

1024

1025

1026

1027

1028

1029

1030

1031

1032

1033

1034

1035

1036

1037

1038

1039

1040

1041

1042

1043

1044

1045

1046

1047

1048

1049

1050

1051

1052

1053

1054

1055

1056

1057

1058

1059

1060

1061

1062

1063

1064

1065

1066

1067

1068

1069
90. Gitelson, A.; Garbuzov, G.; Szilagyi, F.; Mittenzwey, K.H.; Karnieli, A.; Kaiser, A. Quantitative remote sensing methods for real-time monitoring of inland waters quality. Int. J. Remote Sens. 1993, 14, 1269-1295.

91. Le, C.; Li, Y.; Zha, Y.; Wang, Q.; Zhang, H.; Yin, B. Remote sensing of phycocyanin pigment in highly turbid inland waters in Lake Taihu, China. Int. J. Remote Sens. 2011, 32, 8253-8269.

92. Dall'Olmo, G.; Gitelson, A.A. Effect of bio-optical parameter variability and uncertainties in reflectance measurements on the remote estimation of chlorophyll-a concentration in turbid productive waters: modeling results. Appl. Opt. 2006, 45, 3577.

93. Lunetta, R.S.; Schaeffer, B.A.; Stumpf, R.P.; Keith, D.; Jacobs, S.A.; Murphy, M.S. Evaluation of cyanobacteria cell count detection derived from MERIS imagery across the eastern USA. Remote Sens. Environ. 2015, 157, 2434.

94. Oyama, Y.; Matsushita, B.; Fukushima, T. Distinguishing surface cyanobacterial blooms and aquatic macrophytes using Landsat/TM and ETM+ shortwave infrared bands. Remote Sens. Environ. 2015, 157, 35-47.

95. Kudela, R.M.; Palacios, S.L.; Austerberry, D.C.; Accorsi, E.K.; Guild, L.S.; Torres-Perez, J. Application of hyperspectral remote sensing to cyanobacterial blooms in inland waters. Remote Sens. Environ. 2015, 167, 196205.

96. Medina-Cobo, M.; Domínguez, J.A.; Quesada, A.; de Hoyos, C. Estimation of cyanobacteria biovolume in water reservoirs by MERIS sensor. Water Res. 2014, 63, 10-20.

97. Sheela, A.M.; Letha, J.; Joseph, S.; Ramachandran, K.K.; Sanalkumar, S.P. Trophic state index of a lake system using IRS (P6-LISS III) satellite imagery. Environ. Monit. Assess. 2011, 177, 575-592.

98. Curtarelli, M.P.; Ogashawara, I.; Alcântara, E.H.; Stech, J.L. Coupling remote sensing bio-optical and threedimensional hydrodynamic modeling to study the phytoplankton dynamics in a tropical hydroelectric reservoir. Remote Sens. Environ. 2015, 157, 185-198.

99. Hedger, R.; Nils, O.; Malthus, T.; Atkinson, P. Coupling remote sensing with computational fluid dynamics modelling to estimate lake chlorophyll-a concentration. Remote Sens. Environ. 2002, 79, 116-122.

100. Zhang, H.; Hu, W.; Gu, K.; Li, Q.; Zheng, D.; Zhai, S. An improved ecological model and software for short-term algal bloom forecasting. Environ. Model. Softw. 2013, 48, 152-162.

101. Bresciani, M.; Bolpagni, R.; Laini, A.; Matta, E.; Bartoli, M.; Giardino, C. Multitemporal analysis of algal blooms with MERIS images in a deep meromictic lake. Eur. J. Remote Sens. 2013, 46, 445-458.

102. Rügner, H.; Schwientek, M.; Beckingham, B.; Kuch, B.; Grathwohl, P. Turbidity as a proxy for total suspended solids (TSS) and particle facilitated pollutant transport in catchments. Environ. Earth Sci. 2013, 69, 373-380.

103. Nasrabadi, T.; Ruegner, H.; Sirdari, Z.Z.; Schwientek, M.; Grathwohl, P. Using total suspended solids (TSS) and turbidity as proxies for evaluation of metal transport in river water. Appl. Geochemistry 2016, 68, 1-9.

104. Julian, J.P.; Doyle, M.W.; Stanley, E.H. Empirical modeling of light availability in rivers. J. Geophys. Res. Biogeosciences 2008, 113, 1-16.

105. Mendonça, R.; Müller, R.A.; Clow, D.; Verpoorter, C.; Raymond, P.; Tranvik, L.J.; Sobek, S. Organic carbon burial in global lakes and reservoirs. Nat. Commun. 2017, 8, 1-6.

106. Adrian, R.; O’Reilly, C.M.; Zagarese, H.; Baines, S.B.; Hessen, D.O.; Keller, W.; Livingstone, D.M.; Sommaruga, R.; Straile, D.; Van Donk, E.; et al. Lakes as sentinels of climate change. Limnol. Oceanogr. 2009, 54, $2283-2297$.

107. Cole, J.J.; Prairie, Y.T.; Caraco, N.F.; McDowell, W.H.; Tranvik, L.J.; Striegl, R.G.; Duarte, C.M.; Kortelainen, P.; Downing, J.A.; Middelburg, J.J.; et al. Plumbing the global carbon cycle: Integrating inland waters into the terrestrial carbon budget. Ecosystems 2007, 10, 171-184.

108. Downing, J.A.; Prairie, Y.T.; Cole, J.J.; Duarte, C.M.; Tranvik, L.J.; Striegl, R.G.; McDowell, W.H.; Kortelainen, P.; Caraco, N.F.; Melack, J.M.; et al. The global abundance and size distribution of lakes, ponds, and impoundments. Limnol. Oceanogr. 2006, 51, 2388-2397.

109. Verpoorter, C.; Kutser, T.; Seekell, D.A.; Tranvik, L.J. A global inventory of lakes based on high-resolution satellite imagery. Geophys. Res. Lett. 2014, 41, 6396-6402.

110. Bilotta, G.S.; Brazier, R.E. Understanding the influence of suspended solids on water quality and aquatic biota. Water Res. 2008, 42, 2849-2861.

111. Kefford, B.J.; Zalizniak, L.; Dunlop, J.E.; Nugegoda, D.; Choy, S.C. How are macroinvertebrates of slow flowing lotic systems directly affected by suspended and deposited sediments? Environ. Pollut. 2010, 158, 543-550.

112. Overeem, I.; Hudson, B.D.; Syvitski, J.P.M.; Mikkelsen, A.B.; Hasholt, B.; van den Broeke, M.R.; Noël, B.P.Y.; Morlighem, M. Substantial export of suspended sediment to the global oceans from glacial erosion in Greenland. Nat. Geosci. 2017, ngeo3046. 
1070

1071

1072

1073

1074

1075

1076

1077

1078

1079

1080

1081

1082

1083

1084

1085

1086

1087

1088

1089

1090

1091

1092

1093

1094

1095

1096

1097

1098

1099

1100

1101

1102

1103

1104

1105

1106

1107

1108

1109

1110

1111

1112

1113

1114

1115

1116

1117

1118

1119

1120

1121

1122
113. Syvitski, J.P.M. Impact of Humans on the Flux of Terrestrial Sediment to the Global Coastal Ocean. Science (80-. ). 2005, 308, 376-380.

114. Spyrakos, E.; O’Donnell, R.; Hunter, P.D.; Miller, C.; Scott, M.; Simis, S.G.H.; Neil, C.; Barbosa, C.C.F.; Binding, C.E.; Bradt, S.; et al. Optical types of inland and coastal waters. Limnol. Oceanogr. 2017.

115. Novo, E.M.; Hansom, J.D.; Curran, P.J. The effect of sediment type on the relationship between reflectance and suspended sediment concentration. Int. J. Remote Sens. 1989, 10, 1283-1289.

116. Shi, K.; Li, Y.; Li, L.; Lu, H. Absorption characteristics of optically complex inland waters: Implications for water optical classification. J. Geophys. Res. Biogeosciences 2013, 118, 860-874.

117. Brando, V.E.; Braga, F.; Zaggia, L.; Giardino, C.; Bresciani, M.; Matta, E.; Bellafiore, D.; Ferrarin, C.; Maicu, F.; Benetazzo, A.; et al. High-resolution satellite turbidity and sea surface temperature observations of river plume interactions during a significant flood event. Ocean Sci. 2015, 11, 909-920.

118. Pereira, L.S.F.F.; Andes, L.C.; Cox, A.L.; Ghulam, A. Measuring Suspended-Sediment Concentration and Turbidity in the Middle Mississippi and Lower Missouri Rivers using Landsat Data. JAWRA J. Am. Water Resour. Assoc. 2017, 63103, 1-11.

119. Telmer, K.; Costa, M.; Angélica, R.S.; Araujo, E.S.; Maurice, Y. The source and fate of sediment and mercury in the Tapajos River, Para, Brazilian Amazon: Ground- and space-based evidence. J. Environ. Manage. 2006, 81, 101113.

120. Volpe, V.; Silvestri, S.; Marani, M. Remote sensing retrieval of suspended sediment concentration in shallow waters. Remote Sens. Environ. 2011, 115, 44-54.

121. Sobek, S.; Tranvik, L.J.; Prairie, Y.T.; Cole, J.J. Patterns and regulation of dissolved organic carbon: An analysis of 7,500 widely distributed lakes. 2007, 52, 1208-1219.

122. Tranvik, L.J.; Downing, J.A.; Cotner, J.B.; Loiselle, S.A.; Striegl, R.G.; Ballatore, T.J.; Dillon, P.; Finlay, K.; Fortino, K.; Knoll, L.B.; et al. Lakes and reservoirs as regulators of carbon cycling and climate. Limnol. Oceanogr. 2009, 54, 2298-2314.

123. Wen, Z.; Song, K.; Shang, Y.; Fang, C.; Li, L.; Lv, L.; Lv, X.; Chen, L. Carbon dioxide emissions from lakes and reservoirs of China: A regional estimate based on the calculated pCO2. Atmos. Environ. 2017, 170, 71-81.

124. McDonald, C.P.; Stets, E.G.; Striegl, R.G.; Butman, D. Inorganic carbon loading as a primary driver of dissolved carbon dioxide concentrations in the lakes and reservoirs of the contiguous United States. Global Biogeochem. Cycles 2013, 27, 285-295.

125. Raymond, P.A.; Hartmann, J.; Lauerwald, R.; Sobek, S.; McDonald, C.; Hoover, M.; Butman, D.; Striegl, R.; Mayorga, E.; Humborg, C.; et al. Global carbon dioxide emissions from inland waters. Nature 2013, 503, 355.

126. del Vecchio, R.; Blough, N. V Influence of Ultraviolet Radiation on the Chromophoric Dissolved Organic Matter in Natural Waters. In Proceedings of the Environmental UV Radiation: Impact on Ecosystems and Human Health and Predictive Models; Ghetti, F., Checcucci, G., Bornman, J.F., Eds.; Springer Netherlands: Dordrecht, 2006; pp. 203-216.

127. Thrane, J.-E.; Hessen, D.O.; Andersen, T. The Absorption of Light in Lakes: Negative Impact of Dissolved Organic Carbon on Primary Productivity. Ecosystems 2014, 17, 1040-1052.

128. Houser, J.N. Water color affects the stratification, surface temperature, heat content, and mean epilimnetic irradiance of small lakes. Can. J. Fish. Aquat. Sci. 2006, 63, 2447-2455.

129. Kutser, T.; Alikas, K.; Kothawala, D.N.; Köhler, S.J. Impact of iron associated to organic matter on remote sensing estimates of lake carbon content. Remote Sens. Environ. 2015, 156, 109-116.

130. Olmanson, L.G.; Brezonik, P.L.; Finlay, J.C.; Bauer, M.E. Comparison of Landsat 8 and Landsat 7 for regional measurements of CDOM and water clarity in lakes. Remote Sens. Environ. 2016, 185, 119-128.

131. Bricaud, A.; Morel, A.; Prieur, L. Absorption by dissolved organic matter of the sea (yellow substance) in the UV and visible domains1. Limnol. Oceanogr. 1981, 26, 43-53.

132. Kutser, T.; Pierson, D.C.; Tranvik, L.; Reinart, A.; Sobek, S.; Kallio, K. Using Satellite Remote Sensing to Estimate the Colored Dissolved Organic Matter Absorption Coefficient in Lakes. Ecosystems 2005, 8, 709-720.

133. Kutser, T.; Tranvik, L.; Pierson, D.C. Variations in colored dissolved organic matter between boreal lakes studied by satellite remote sensing. J. Appl. Remote Sens. 2009, 3, 033538.

134. Brezonik, P.; Menken, K.D.; Bauer, M. Landsat-based remote sensing of lake water quality characteristics, including chlorophyll and colored dissolved organic matter (CDOM). Lake Reserv. Manag. 2005, 21, $373-382$.

135. Chang, N.-B.; Vannah, B. Monitoring the total organic carbon concentrations in a lake with the integrated data fusion and machine-learning (IDFM) technique. SPIE Opt. Eng. + Appl. 2012, 8513. 
1123

1124

1125

1126

1127

1128

1129

1130

1131

1132

1133

1134

1135

1136

1137

1138

1139

1140

1141

1142

1143

1144

1145

1146

1147

1148

1149

1150

1151

1152

1153

1154

1155

1156

1157

1158

1159

1160

1161

1162

1163

1164

1165

1166

1167

1168

1169

1170

1171

1172

1173

1174

1175
136. Kutser, T.; Verpoorter, C.; Paavel, B.; Tranvik, L.J. Estimating lake carbon fractions from remote sensing data. Remote Sens. Environ. 2015, 157, 138-146.

137. Griffin, C.G.; Finlay, J.C.; Brezonik, P.L.; Olmanson, L.; Hozalski, R.M. Limitations on using CDOM as a proxy for DOC in temperate lakes. Water Res. 2018, 144, 719-727.

138. Griffin, C.G.; Frey, K.E.; Rogan, J.; Holmes, R.M. Spatial and interannual variability of dissolved organic matter in the Kolyma River, East Siberia, observed using satellite imagery. J. Geophys. Res. Biogeosciences 2011, 116, 112.

139. G. Coble, P. Marine Optical Biogeochemistry: The Chemistry of Ocean Color. Chem. Rev. 2007, 107, 402-418.

140. Cialdi, A.; Secchi, P.A. Sur la transparence de la mer. Comptes rendus Hebd. sceances l'Academie des Sci. 1865, 61, 100-104.

141. Wernand, M.R. On the history of the Secchi disc. J. Eur. Opt. Soc. 2010, 5.

142. Mazumder, A.; Taylor, W.D. Thermal Structure of Lakes Varying in Size and Water Clarity. Limnol. Oceanogr. 1994, 39, 968-976.

143. Gunn, J.M.; Snucins, E.D.E.D.; Yan, N.D.; Arts, M.T. Use of water clarity to monitor the effects of climate change and other stressors on oligotrophic lakes. Environ. Monit. Assess. 2001, 67, 69-88.

144. Heiskanen, J.J.; Mammarella, I.; Ojala, A.; Stepanenko, V.; Erkkilä, K.M.; Miettinen, H.; Sandström, H.; Eugster, W.; Leppäranta, M.; Järvinen, H.; et al. Effects of water clarity on lake stratification and lake-atmosphere heat exchange. J. Geophys. Res. 2015, 120, 7412-7428.

145. Obrador, B.; Staehr, P.A.; Christensen, J.P.C. Vertical patterns of metabolism in three contrasting stratified lakes. Limnol. Oceanogr. 2014, 59, 1228-1240.

146. Schwarz, A.M.; Hawes, I. Effects of changing water clarity on characean biomass and species composition in a large oligotrophic lake. Aquat. Bot. 1997, 56, 169-181.

147. Izagirre, O.; Serra, A.; Guasch, H.; Elosegi, A. Effects of sediment deposition on periphytic biomass, photosynthetic activity and algal community structure. Sci. Total Environ. 2009, 407, 5694-5700.

148. Rose, K.C.; Greb, S.R.; Diebel, M.; Turner, M.G. Annual precipitation regulates spatial and temporal drivers of lake water clarity: Ecol. Appl. 2017, 27, 632-643.

149. Nelson, S.A.C.; Soranno, P.A.; Cheruvelil, K.S.; Batzli, S.A.; Skole, D.L. Regional Assessment of lake water clarity using satellite remote sensing. J. Limnol. 2003, 62, 27-32.

150. Hicks, B.J.; Stichbury, G.A.; Brabyn, L.K.; Allan, M.G.; Ashraf, S. Hindcasting water clarity from Landsat satellite images of unmonitored shallow lakes in the Waikato region, New Zealand. Environ. Monit. Assess. 2013, 185, 7245-7261.

151. Bayley, S.E.; Creed, I.F.; Sass, G.Z.; Wong, A.S. Frequent regime shifts in trophic states in shallow lakes on the Boreal Plain: Alternative "unstable" states? Limnol. Oceanogr. 2007, 52, 2002-2012.

152. Wu, G.; De Leeuw, J.; Skidmore, A.K.; Prins, H.H.T.; Liu, Y. Comparison of MODIS and Landsat TM5 images for mapping tempo-spatial dynamics of Secchi disk depths in Poyang Lake National Nature Reserve, China. Int. J. Remote Sens. 2008, 29, 2183-2198.

153. Verdin, J.P. Bureau of Reclamation Monitoring Water Quality Conditions in a Large Western Reservoir with Landsat Imagery. Photogramm. Eng. Remote Sensing 1985, 51, 343-353.

154. Hutchinson, E. Marginalia: Eutrophication: The scientific background of a contemporary practical problem on JSTOR. Sigma Xi, Sci. Res. Soc. 1973, 61, 269-279.

155. Carlson, R.E. A trophic state index for lakes. Limnol. Oceanogr. 1977, 22, 361-369.

156. Megard, R.O.; Settles, J.C.; Boyer, H.A.; Combs, W.S. Light, Secchi Disks, and Trophic States. Limnol. Oceanogr. 1980, 25, 373-377.

157. Olmanson, L.G.; Bauer, M.E.; Brezonik, P.L. A 20-year Landsat water clarity census of Minnesota's 10,000 lakes. Remote Sens. Environ. 2008, 112, 4086-4097.

158. Peckham, S.D.; Chipman, J.W.; Lillesand, T.M.; Dodson, S.I. Alternate stable states and the shape of the lake trophic distribution. Hydrobiologia 2006, 571, 401-407.

159. Politi, E.; Cutler, M.E.J.; Rowan, J.S. Evaluating the spatial transferability and temporal repeatability of remotesensing-based lake water quality retrieval algorithms at the European scale: a meta-analysis approach. Int. J. Remote Sens. 2015, 36, 2995-3023.

160. Carpenter, D.J.; Carpenter, S.M. Modeling inland water quality using Landsat data. Remote Sens. Environ. 1983, 13, 345-352.

161. Mishra, S.; Mishra, D.R. Normalized difference chlorophyll index: A novel model for remote estimation of 
1176

1177

1178

1179

1180

1181

1182

1183

1184

1185

1186

1187

1188

1189

1190

1191

1192

1193

1194

1195

1196

1197

1198

1199

1200

1201

1202

1203

1204

1205

1206

1207

1208

1209

1210

1211

1212

1213

1214

1215

1216

1217

1218

1219

1220

1221

1222

1223

1224

1225

1226

1227

1228 chlorophyll-a concentration in turbid productive waters. Remote Sens. Environ. 2012, 117, $394-406$.

162. Gower, J.; King, S.; Borstad, G.; Brown, L. Detection of intense plankton blooms using the $709 \mathrm{~nm}$ band of the MERIS imaging spectrometer. Int. J. Remote Sens. 2005, 26, 2005-2012.

163. $\mathrm{Hu}, \mathrm{C}$. A novel ocean color index to detect floating algae in the global oceans. Remote Sens. Environ. 2009, 113, 2118-2129.

164. Shahzad, M.I.; Meraj, M.; Nazeer, M.; Zia, I.; Inam, A.; Mehmood, K.; Zafar, H. Empirical estimation of suspended solids concentration in the Indus Delta Region using Landsat-7 ETM+ imagery. J. Environ. Manage. 2018, 209, 254-261.

165. Huang, C.; Li, Y.; Yang, H.; Sun, D.; Yu, Z.; Zhang, Z.; Chen, X.; Xu, L. Detection of algal bloom and factors influencing its formation in Taihu Lake from 2000 to 2011 by MODIS. Environ. Earth Sci. 2014, 71, 3705-3714.

166. Morel, A. BIO-OPTICAL MODELS. 2001, 385-394.

167. Morel Prieur, L., A. Analysis of variations in ocean color. Limnol. Ocean. 1977, 22, 709-725.

168. Philpot, W.D. Radiative transfer in stratified waters: a single-scattering approximation for irradiance. Appl. Opt. 1987, 26, 4123.

169. Gordon, H.R.; Brown, O.B.; Evans, R.H.; Brown, J.W.; Smith, R.C.; Baker, K.S.; Clark, D.K. A semianalytic radiance model of ocean color. J. Geophys. Res. 1988, 93, 10909.

170. Gordon, H.R.; Brown, O.B.; Jacobs, M.M. Computed Relationships Between the Inherent and Apparent Optical Properties of a Flat Homogeneous Ocean. Appl. Opt. 1975, 14, 417.

171. Mobley, C.D.; Sundman, L.K. HydroLight 5 EcoLight 5 Technical documentation. Sequoia Sci. Inc. 2008.

172. Dekker, A.G.; Seyhan, E.; Malthus, T.J. Quantitative Modeling of Inland Water Quality for High-Resolution MSS Systems. IEEE Trans. Geosci. Remote Sens. 1991, 29, 89-95.

173. Kutser, T.; Arst, H. Remote sensing reflectance model of optically active components of turbid waters. In Proceedings of the Proc. SPIE 2319, Oceanic Remote Sensing and Sea Ice Monitoring; 1994; Vol. 2319, pp. 85-91.

174. Heege, T.; Kiselev, V.; Wettle, M.; Hung, N.N. Operational multi-sensor monitoring of turbidity for the entire Mekong Delta. Int. J. Remote Sens. 2014, 35, 2910-2926.

175. Lymburner, L.; Botha, E.; Hestir, E.; Anstee, J.; Sagar, S.; Dekker, A.; Malthus, T. Landsat 8: Providing continuity and increased precision for measuring multi-decadal time series of total suspended matter. Remote Sens. Environ. 2016, 185, 108-118.

176. Zhou, X.; Marani, M.; Albertson, J.; Silvestri, S.; Zhou, X.; Marani, M.; Albertson, J.D.; Silvestri, S. Hyperspectral and Multispectral Retrieval of Suspended Sediment in Shallow Coastal Waters Using Semi-Analytical and Empirical Methods. Remote Sens. 2017, 9, 393.

177. Dekker, A.G.; Vos, R.J.; Peters, S.W.M. Analytical algorithms for lake water TSM estimation for retrospective analyses of TM and SPOT sensor data. Int. J. Remote Sens. 2002, 23, 15-35.

178. Dekker, A.G.; Vos, R.J.; Peters, S.W.M. Comparison of remote sensing data, model results and in situ data for total suspended matter (TSM) in the southern Frisian lakes. Sci. Total Environ. 2001, 268, 197-214.

179. Olden, J.D.; Lawler, J.J.; Poff, N.L. Machine Learning Methods Without Tears: A Primer for Ecologists. Q. Rev. Biol. 2008, 83, 171-193.

180. Camps-Valls, G. Machine learning in remote sensing data processing. In Proceedings of the 2009 IEEE International Workshop on Machine Learning for Signal Processing; IEEE, 2009; pp. 1-6.

181. Lary, D.J.; Alavi, A.H.; Gandomi, A.H.; Walker, A.L. Machine learning in geosciences and remote sensing. Geosci. Front. 2016, 7, 3-10.

182. Imen, S.; Chang, N. Bin; Yang, Y.J. Developing the remote sensing-based early warning system for monitoring TSS concentrations in Lake Mead. J. Environ. Manage. 2015, 160, 73-89.

183. Song, K. Water quality monitoring using Landsat Themate Mapper data with empirical algorithms in Chagan Lake, China. J. Appl. Remote Sens. 2011, 5, 053506.

184. Schiller, H.; Doerffer, R. Neural network for emulation of an inverse model operational derivation of Case II water properties from MERIS data. Int. J. Remote Sens. 1999, 20, 1735-1746.

185. Song, K.; Li, L.; Tedesco, L.P.; Li, S.; Duan, H.; Liu, D.; Hall, B.E.; Du, J.; Li, Z.; Shi, K.; et al. Remote estimation of chlorophyll-a in turbid inland waters: Three-band model versus GA-PLS model. Remote Sens. Environ. 2013, 136, 342-357.

186. Chang, N.-B.; Vannah, B.W.; Yang, Y.J.; Elovitz, M. Integrated data fusion and mining techniques for monitoring total organic carbon concentrations in a lake. Int. J. Remote Sens. 2014, 35, 1064-1093.

187. Sun, D.; Qiu, Z.; Li, Y.; Shi, K.; Gong, S. Detection of Total Phosphorus Concentrations of Turbid Inland Waters 
Using a Remote Sensing Method. Water, Air, Soil Pollut. 2014, 225, 1953.

188. Lin, S.; Novitski, L.N.; Qi, J.; Stevenson, R.J. Landsat TM/ETM+ and machine-learning algorithms for limnological studies and algal bloom management of inland lakes. J. Appl. Remote Sens. 2018, 12, 1-17.

189. Qi, L.; Hu, C.; Duan, H.; Barnes, B.B.; Ma, R. An EOF-based algorithm to estimate chlorophyll a concentrations in taihu lake from MODIS land-band measurements: Implications for near real-time applications and forecasting models. Remote Sens. 2014, 6, 10694-10715.

190. Duan, H.; Tao, M.; Loiselle, S.A.; Zhao, W.; Cao, Z.; Ma, R.; Tang, X. MODIS observations of cyanobacterial risks in a eutrophic lake: Implications for long-term safety evaluation in drinking-water source. Water Res. 2017, 122, 455-470.

191. Hastie, T.T. The Elements of Statistical Learning. Math. Intell. 2009, 27, 83-85.

192. Rocha, A.D.; Groen, T.A.; Skidmore, A.K.; Darvishzadeh, R.; Willemen, L. The Naïve Overfitting Index Selection (NOIS): A new method to optimize model complexity for hyperspectral data. ISPRS J. Photogramm. Remote Sens. 2017, 133, 61-74.

193. Xiang, B.; Song, J.-W.; Wang, X.-Y.; Zhen, J. Improving the accuracy of estimation of eutrophication state index using a remote sensing data-driven method: A case study of Chaohu Lake, China. Water SA 2015, 41, 753.

194. Concha, J.A.; Schott, J.R. Retrieval of color producing agents in Case 2 waters using Landsat 8. Remote Sens. Environ. 2016, 185, 95-107.

195. Pahlevan, N.; Sarkar, S.; Franz, B.A.; Balasubramanian, S. V.; He, J. Sentinel-2 MultiSpectral Instrument (MSI) data processing for aquatic science applications: Demonstrations and validations. Remote Sens. Environ. 2017, 201, 47-56.

196. Brivio, P.A.; Giardino, C.; Zilioli, E. Validation of satellite data for quality assurance in lake monitoring applications. Sci. Total Environ. 2001, 268, 3-18.

197. Gordon, H.R.; Wang, M. Retrieval of water-leaving radiance and aerosol optical thickness over the oceans with SeaWiFS: a preliminary algorithm. Appl. Opt. 1994, 33, 443.

198. Schroeder, T.; Behnert, I.; Schaale, M.; Fischer, J.; Doerffer, R. Atmospheric correction algorithm for MERIS above case-2 waters. Int. J. Remote Sens. 2007, 28, 1469-1486.

199. Vanhellemont, Q.; Ruddick, K. Atmospheric correction of metre-scale optical satellite data for inland and coastal water applications. Remote Sens. Environ. 2018, 216, 586-597.

200. Wang, M.; Son, S.; Zhang, Y.; Shi, W. Remote sensing of water optical property for China's inland lake taihu using the SWIR atmospheric correction with 1640 and $2130 \mathrm{~nm}$ bands. IEEE J. Sel. Top. Appl. Earth Obs. Remote Sens. 2013, 6, 2505-2516.

201. Novoa, S.; Doxaran, D.; Ody, A.; Vanhellemont, Q.; Lafon, V.; Lubac, B.; Gernez, P. Atmospheric corrections and multi-conditional algorithm for multi-sensor remote sensing of suspended particulate matter in low-to-high turbidity levels coastal waters. Remote Sens. 2017, 9.

202. Pahlevan, N.; Chittimalli, S.K.; Balasubramanian, S. V.; Vellucci, V. Sentinel-2/Landsat-8 product consistency and implications for monitoring aquatic systems. Remote Sens. Environ. 2019, 220, 19-29.

203. Kiselev, V.; Bulgarelli, B.; Heege, T. Sensor independent adjacency correction algorithm for coastal and inland water systems. Remote Sens. Environ. 2015, 157, 85-95.

204. Garaba, S.P.; Zielinski, O. An assessment of water quality monitoring tools in an estuarine system. Remote Sens. Appl. Soc. Environ. 2015, 2, 1-10.

205. Garaba, S..; Badewien, T.H.; Braun, A.; Schulz, A.C.; Zielinksi, O. Using ocean colour remote sensing products to estimate turbidity at the Wadden sea time series station Spiekeroog. J. Eur. Opt. Soc. 2014, 9.

206. Kutser, T.; Vahtmäe, E.; Praks, J. A sun glint correction method for hyperspectral imagery containing areas with non-negligible water leaving NIR signal. Remote Sens. Environ. 2009, 113, 2267-2274.

207. Martin, J.; Eugenio, F.; Marcello, J.; Medina, A. Automatic sun glint removal of multispectral high-resolution WorldView-2 imagery for retrieving coastal shallow water parameters. Remote Sens. 2016, 8, 1-16.

208. Doxaran, D.; Froidefond, J.M.; Castaing, P. A reflectance band ratio used to estimate suspended matter concentrations in sediment-dominated coastal waters A re ectance band ratio used to estimate suspended matter concentrations in sediment-dominated coastal w. Int. J. Remote Sens. 2002, 23, 5079-5085.

209. Bukata, R.P. Retrospection and introspection on remote sensing of inland water quality : "Like Déjà Vu All Over Again." J. Great Lakes Res. 2013, 39, 2-5.

210. Downing, J.A. Limnology and oceanography: Two estranged twins reuniting by global change. Inl. Waters 2014, 4, 215-232. 
211. Palmer, S.C.J.; Kutser, T.; Hunter, P.D. Remote sensing of inland waters: Challenges, progress and future directions. Remote Sens. Environ. 2015, 157, 1-8.

212. Aria, M.; Cuccurullo, C. bibliometrix: An R-tool for comprehensive science mapping analysis. J. Informetr. 2017, 11, 959-975.

213. Bornmann, L.; Mutz, R. Growth rates of modern science: A bibliometric analysis based on the number of publications and cited references. J. Assoc. Inf. Sci. Technol. 2015, 66, 2215-2222.

214. Wulder, M.A.; Masek, J.G.; Cohen, W.B.; Loveland, T.R.; Woodcock, C.E. Opening the archive: How free data has enabled the science and monitoring promise of Landsat. Remote Sens. Environ. 2012, 122, 2-10.

215. Willmott, C.J. On the validation of Models. Phys. Geogr. 1981, 2, 184-194.

216. Alikas, K.; Reinart, A. Validation of the MERIS products on large European lakes: Peipsi, Vänern and Vättern. Hydrobiologia 2008, 599, 161-168.

217. Kallio, K.; Koponen, S.; Ylöstalo, P.; Kervinen, M.; Pyhälahti, T.; Attila, J. Validation of MERIS spectral inversion processors using reflectance, IOP and water quality measurements in boreal lakes. Remote Sens. Environ. 2015, 157, 147-157.

218. Okullo, W.; Hamre, B.; Frette, O.; Stamnes, J.J.; Sorensen, K.; Ssenyonga, T.; Hokedal, J.; Stamnes, K.; Steigen, A. Validation of MERIS water quality products in Murchison Bay, Lake Victoria - Preliminary results. Int. J. Remote Sens. 2011, 32, 5541-5563.

219. Therneau, T.; Atkinson, B. rpart: Recursive Partitioning and Regression Trees. 2019.

220. Venables, W.N.; Ripley, B.D. Modern Applied Statistics with S; Fourth.; Springer: New York, 2002; ISBN 0-38795457-0.

221. Pedregosa, F.; Varoquaux, G.; Gramfort, A.; Michel, V.; Thirion, B.; Grisel, O.; Blondel, M.; Müller, A.; Nothman, J.; Louppe, G.; et al. Scikit-learn: Machine Learning in Python. 2011, 12, 2825-2830.

222. Sonnenburg, S.; Braun, M.; Ong, C.S.; Bengio, S.; Botou, L.; Holmes, G.; LeCun, Y.; Muller, K.-R.; Pereira, F.; Rasmussen, C.E.; et al. The Need for Open Source Software in Machine Learning. J. Mach. Learn. Res. 2007, 8, 600-611.

223. Pearson, K. Mathematical contributions to the theory of evolution. III. Regression, heredity, and panmixia. Philos. Trans. R. Soc. London. Ser. A, Contain. Pap. a Math. or Phys. character 1896, 187, 253-318.

224. Olmanson, L.G.; Brezonik, P.L.; Bauer, M.E. Geospatial and temporal analysis of a 20-year record of Landsatbased water clarity in Minnesota's 10,000 lakes. J. Am. Water Resour. Assoc. 2014, 50, 748-761.

225. Ng, S.M.Y.; Antenucci, J.P.; Hipsey, M.R.; Tibor, G.; Zohary, T. Physical controls on the spatial evolution of a dinoflagellate bloom in a large lake. Limnol. Oceanogr. 2011, 56, 2265-2281.

226. Wang, M.; Nim, C.J.; Son, S.H.; Shi, W. Characterization of turbidity in Florida's Lake Okeechobee and Caloosahatchee and St. Lucie Estuaries using MODIS-Aqua measurements. Water Res. 2012, 46, 5410-5422.

227. Zhu, M.; Paerl, H.W.; Zhu, G.; Wu, T.; Li, W.; Shi, K.; Zhao, L.; Zhang, Y.; Qin, B.; Caruso, A.M. The role of tropical cyclones in stimulating cyanobacterial (Microcystis spp.) blooms in hypertrophic Lake Taihu, China. Harmful Algae 2014, 39, 310-321.

228. Sass, G.Z.; Creed, I.F.; Bayley, S.E.; Devito, K.J. Interannual variability in trophic status of shallow lakes on the Boreal Plain: Is there a climate signal? Water Resour. Res. 2008, 44, 1-11.

229. Cui, L.; Qiu, Y.; Fei, T.; Liu, Y.; Wu, G. Using remotely sensed suspended sediment concentration variation to improve management of Poyang Lake, China. Lake Reserv. Manag. 2013, 29, 47-60.

230. Cui, L.; Wu, G.; Liu, Y. Monitoring the impact of backflow and dredging on water clarity using MODIS images of Poyang Lake, China. Hydrol. Process. 2009, 23, 342-350.

231. Ren, J.; Zheng, Z.; Li, Y.; Lv, G.; Wang, Q.; Lyu, H.; Huang, C.; Liu, G.; Du, C.; Mu, M.; et al. Remote observation of water clarity patterns in Three Gorges Reservoir and Dongting Lake of China and their probable linkage to the Three Gorges Dam based on Landsat 8 imagery. Sci. Total Environ. 2018, 625, 1554-1566.

232. Hou, X.; Feng, L.; Duan, H.; Chen, X.; Sun, D.; Shi, K. Fifteen-year monitoring of the turbidity dynamics in large lakes and reservoirs in the middle and lower basin of the Yangtze River, China. Remote Sens. Environ. 2017, 190, 107-121.

233. Pavelsky, T.M.; Smith, L.C. Remote sensing of suspended sediment concentration, flow velocity, and lake recharge in the Peace-Athabasca Delta, Canada. Water Resour. Res. 2009, 45, 1-16.

234. Long, C.M.; Pavelsky, T.M. Remote sensing of suspended sediment concentration and hydrologic connectivity in a complex wetland environment. Remote Sens. Environ. 2013, 129, 197-209.

235. Sandström, A.; Philipson, P.; Asp, A.; Axenrot, T.; Kinnerbäck, A.; Ragnarsson-Stabo, H.; Holmgren, K. 
1335

1336

1337

1338

1339

1340

1341

1342

1343

1344

1345

1346

1347

1348

1349

1350

1351

1352

1353

1354

1355

1356

1357

1358

1359

1360

1361

1362

1363

1364

1365

1366

1367

1368

1369

1370

1371

1372

1373

1374

1375

1376

1377

1378

1379

1380

1381

1382

1383

1384

1385

1386

1387
Assessing the potential of remote sensing-derived water quality data to explain variations in fish assemblages and to support fish status assessments in large lakes. Hydrobiologia 2016, 780, 71-84.

236. Torbick, N.; Hession, S.; Stommel, E.; Caller, T. Mapping amyotrophic lateral sclerosis lake risk factors across northern New England. Int. J. Health Geogr. 2014, 13.

237. Finger, F.; Knox, A.; Bertuzzo, E.; Mari, L.; Bompangue, D.; Gatto, M.; Rodriguez-Iturbe, I.; Rinaldo, A. Cholera in the Lake Kivu region (DRC): Integrating remote sensing and spatially explicit epidemiological modeling. Water Resour. Res. 2014, 50, 5624-5637.

238. McCullough, I.M.; Loftin, C.S.; Sader, S.A. Landsat imagery reveals declining clarity of Maine's lakes during 1995-2010. Freshw. Sci. 2013, 32, 741-752.

239. Gorelick, N.; Hancher, M.; Dixon, M.; Ilyushchenko, S.; Thau, D.; Moore, R. Google Earth Engine: Planetaryscale geospatial analysis for everyone. Remote Sens. Environ. 2017, 202, 18-27.

240. Fox, J. Aspects of the Social Organization and Trajectory of the R Project. R J. $2009,1$.

241. Read, E.K.; Carr, L.; De Cicco, L.; Dugan, H.A.; Hanson, P.C.; Hart, J.A.; Kreft, J.; Read, J.S.; Winslow, L.A. Water quality data for national-scale aquatic research: The Water Quality Portal. Water Resour. Res. 2017, 53, $1735-1745$.

242. Soranno, P.A.; Bacon, L.C.; Beauchene, M.; Bednar, K.E.; Bissell, E.G.; Boudreau, C.K.; Boyer, M.G.; Bremigan, M.T.; Carpenter, S.R.; Carr, J.W.; et al. LAGOS-NE: A multi-scaled geospatial and temporal database of lake ecological context and water quality for thousands of U.S. lakes. Gigascience 2017, 1-22.

243. Schaeffer, B.A.; liames, J.; Dwyer, J.; Urquhart, E.; Salls, W.; Rover, J.; Seegers, B. An initial validation of Landsat 5 and 7 derived surface water temperature for U.S. lakes, reservoirs, and estuaries. Int. J. Remote Sens. 2018, 00, $1-17$.

244. Srebotnjak, T.; Carr, G.; De Sherbinin, A.; Rickwood, C. A global Water Quality Index and hot-deck imputation of missing data. Ecol. Indic. 2012, 17, 108-119.

245. Ross, M.R.V.; Topp, S.N.; Appling, A.; Yang, X.; Kuhn, C.; Buttman, D.; Simard, M.; Pavelsky, T. AquaSat: a dataset to enable remote sensing of water quality for inland waters. Water Resour. Res.

246. Kneubühler, M.; Damm-Reiser, A. Recent progress and developments in imaging spectroscopy. Remote Sens. 2018, 10, 1-4.

247. Cooley, S.W.; Smith, L.C.; Stepan, L.; Mascaro, J. Tracking dynamic northern surface water changes with highfrequency planet CubeSat imagery. Remote Sens. 2017, 9, 1-21.

248. McCabe, M.F.; Rodell, M.; Alsdorf, D.E.; Miralles, D.G.; Uijlenhoet, R.; Wagner, W.; Lucieer, A.; Houborg, R.; Verhoest, N.E.C.; Franz, T.E.; et al. The future of Earth observation in hydrology. Hydrol. Earth Syst. Sci. 2017, 21, 1-56.

249. Devred, E.; Turpie, K.R.; Moses, W.; Klemas, V. V.; Moisan, T.; Babin, M.; Toro-Farmer, G.; Forget, M.H.; Jo, Y.H. Future retrievals of water column bio-optical properties using the hyperspectral infrared imager (hyspiri). Remote Sens. 2013, 5, 6812-6837.

250. IOCCG. Why Ocean Colour? The Societal Benefits of Ocean-Colour Technology. Platt, T., Hoepffner, N., Stuart, V. and Brown, C. (eds.), Reports of the International Ocean-Colour Coordinating Group, No. 7, 2008;

251. National Academies of Sciences, E. and M. Thriving on Our Changing Planet; National Academies Press: Washington, D.C., 2018; ISBN 978-0-309-46757-5.

252. Poikane, S.; Van Den Berg, M.; Hellsten, S.; De Hoyos, C.; Ortiz-Casas, J.; Pall, K.; Portielje, R.; Phillips, G.; Solheim, A.L.; Tierney, D.; et al. Lake ecological assessment systems and intercalibration for the European Water Framework Directive: Aims, achievements and further challenges. Procedia Environ. Sci. 2011, 9, $153-168$.

253. Wu, G.; de Leeuw, J.; Skidmore, A.K.; Prins, H.H.T.T.; Liu, Y. Concurrent monitoring of vessels and water turbidity enhances the strength of evidence in remotely sensed dredging impact assessment. Water Res. 2007, 41, 3271-3280.

254. Robert, E.; Kergoat, L.; Soumaguel, N.; Merlet, S.; Martinez, J.M.; Diawara, M.; Grippa, M. Analysis of suspended particulate matter and its drivers in Sahelian Ponds and Lakes by remote sensing (landsat and MODIS): Gourma Region, Mali. Remote Sens. 2017, 9.

255. Huang, C.; Guo, Y.; Yang, H.; Li, Y.; Zou, J.; Zhang, M.; Lyu, H.; Zhu, A.; Huang, T. Using Remote Sensing to Track Variation in Phosphorus and Its Interaction with Chlorophyll-a and Suspended Sediment. IEEE J. Sel. Top. Appl. Earth Obs. Remote Sens. 2015, 8, 4171-4180.

256. Duane Nellis, M.; Harrington, J. a.; Wu, J. Remote sensing of temporal and spatial variations in pool size, suspended sediment, turbidity, and Secchi depth in Tuttle Creek Reservoir, Kansas: 1993. Geomorphology 1998, 21, 281-293. 
257. Feng, L.; Hu, C.; Han, X.; Chen, X.; Qi, L. Long-term distribution patterns of chlorophyll-a concentration in China's largest freshwater lake: MERIS full-resolution observations with a practical approach. Remote Sens. 2015, 7, 275-299.

258. Sass, G.Z.; Creed, I.F.; Devito, K.J. Spatial heterogeneity in trophic status of shallow lakes on the Boreal Plain: Influence of hydrologic setting. Water Resour. Res. 2008, 44.

259. Potes, M.; Costa, M.J.; Salgado, R. Satellite remote sensing of water turbidity in Alqueva reservoir and implications on lake modelling. Hydrol. Earth Syst. Sci. 2012, 16, 1623-1633.

Author Contributions: Conceptualization and methodology conducted by S.T., M.R., and T.P. Formal analysis done by S.T, M.R., and D.J. Writing and draft preparation done by S.T. Review and editing done by S.T., M.R., T.P., D.J., and M.S. All authors contributed substantially to the produced work.

Funding: Support for the manuscript was provided by NASA NESSF 80NSSC18K1398. Part of this work was conducted at the Jet Propulsion Laboratory, California Institute of Technology, under a contract with the National Aeronautics and Space Administration.

Acknowledgments We are grateful to all those who provided feedback on this manuscript.

\section{Appendix A: Supplemental Information}

$$
\text { The inland water quality remote sensing index can be found in its entirety here: }
$$

\section{https://docs.google.com/spreadsheets/d/1GMka4B-E16FmXBWjv0lhBN0T-} 07oeZT4riepMMHvZz4/edit?usp=sharingusp=sharing

The code and data for all analysis and figures can be found here:

\section{https://github.com/SimonTopp/rs.iw.review}

The supplemental tables below describe in detail the recorded metrics of each included study as well as a description of the studies identified as applying remote sensing to better understand the dynamics and impacts of inland water quality. 
Index Parameter

Identifying information

Locational Information

Study Scale

Study Period

Sensor Information

Atmospheric Correction

Parameters

Waterbody Type

Modeling Approach

Information

Number of Methodology

Figures

Number of Validation

Figures

Number of Trend, Impact, and Driver Figures

Paper Category

Model Fit Error

Model Validation Error
Parameter Description

Composed of an index number, author(s), journal, title, year of publication, DOI, and total citation count pulled from

\section{SCOPUS.}

Country of focus and central latitude and longitude of the study area.

The order of magnitude of the study area in $\mathrm{km} 2$. The surface area of the waterbody for single waterbody studies, total area of all waterbodies for spatially discontinuous studies, or the total area of the entire region if the study area was contiguous. Represented as $10^{\wedge} 1 \mathrm{~km} 2,10^{\wedge} 2 \mathrm{~km} 2,10^{\wedge} 3 \mathrm{~km} 2$, etc.

The duration of the study. If no temporal analysis was conducted than the period was marked na. Total study length was determined as the date of the first image to the date of the final image.

Satellite and/or airborne sensors utilized and the spectral resolution of each sensor (hyperspectral or multispectral)

A binary yes/no regarding the application of an atmospheric correction for the final model.

The water quality parameters included in the study.

The waterbody of focus (Rivers, Lakes/Reservoirs, Estuaries, or Deltas)

The model inputs, chosen modelling methodology, and total number of models used. Also included is information on if different modelling approaches were compared (i.e. empirical vs semi-analytical approaches).

The total count of figures focused on background information. These include study area maps, flow charts, tables with input data, and other figures depicting the theory or method behind the modelling approach.

The total count of figures focused on model validation. These include tables of error metrics and actual vs. predicted plots.

The total count of figures and tables depicting some spatial or temporal trend. These include maps, timelines, figures depicting correlations between water quality parameters and climatic or anthropogenic drivers, and figures or tables examining the impacts of changing water quality parameters on ecological or anthropogenic systems.

The final classification of the paper based on total figure counts and proposed hypothesis/science questions.

Reported error metrics for model fit.

Reported error metrics for model validation based on data not used in model development.

Table S1. Summary of collected information for the detailed literature review index. 


\begin{tabular}{|c|c|c|c|c|c|c|c|}
\hline & Author & 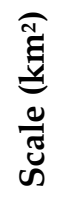 & 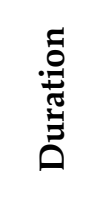 & 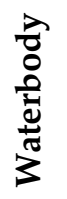 & 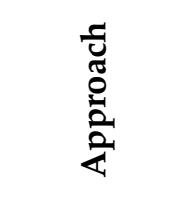 & 节 & Analysis Summary \\
\hline \multirow{6}{*}{ 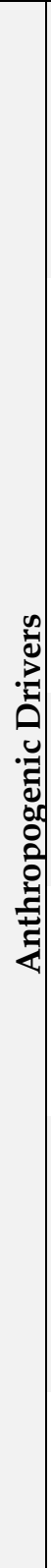 } & $\begin{array}{c}\text { Ren et al., } \\
2018\end{array}$ & $\sum_{0}^{m}$ & 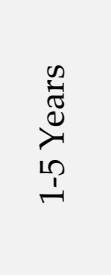 & 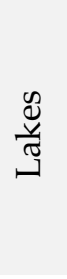 & Empirical & SDD & $\begin{array}{l}\text { Examines spatiotemporal variations } \\
\text { in water clarity and sediment } \\
\text { discharge connected to the Three } \\
\text { Gorges Dam. Finds that certain areas } \\
\text { have inversely corelated clarity } \\
\text { driven by surface flow dynamics. }\end{array}$ \\
\hline & $\begin{array}{c}\text { Hou et al., } \\
2017\end{array}$ & 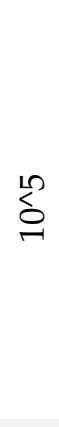 & 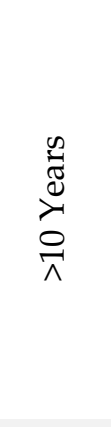 & 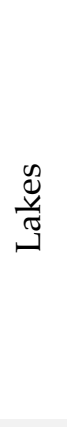 & Empirical & TSS & $\begin{array}{l}\text { Examines the spatiotemporal } \\
\text { response of TSS in the Yangtze River } \\
\text { Basin to the construction of the Three } \\
\text { Gorges Dam. Found that the } \\
\text { reservoir construction drove varying } \\
\text { regional effects, and that recent } \\
\text { improvements in TSS are likely } \\
\text { correlated with increased NDVI in } \\
\text { the area. }\end{array}$ \\
\hline & $\begin{array}{l}\text { Cui et al., } \\
2013\end{array}$ & $\sum_{0}^{\infty}$ & 을 & 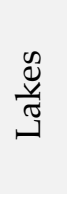 & Empirical & TSS & $\begin{array}{c}\text { Examines the spatiotemporal trends } \\
\text { of TSS in a Chinese lake and how it } \\
\text { correlates with dredging activities } \\
\text { and climactic drivers. }\end{array}$ \\
\hline & $\begin{array}{l}\text { McCulloug } \\
\text { h et al., } \\
2012\end{array}$ & $\underbrace{+1}_{-}$ & 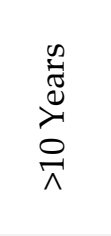 & 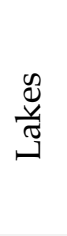 & Empirical & SDD & $\begin{array}{l}\text { Utilizes Landsat data to examine } \\
\text { water clarity in Maine over } 15 \text { years. } \\
\text { Finds that decreased clarity is } \\
\text { somewhat correlated to the presence } \\
\text { of timber harvesting in a watershed. }\end{array}$ \\
\hline & $\begin{array}{l}\text { Cui, Wu, } \\
\text { and Liu, } \\
2009\end{array}$ & $\sum_{0}^{\infty}$ & 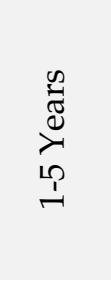 & $\begin{array}{l}\mathscr{\mathscr { J }} \\
\stackrel{\tilde{\sigma}}{\Xi} \\
\end{array}$ & Empirical & SDD & $\begin{array}{l}\text { Examines the interactions between } \\
\text { elevated TSS levels driven by river } \\
\text { backflow into Poyang Lake (China) } \\
\text { and lake dredging. Finds that the } \\
\text { combined impact is greater than } \\
\text { either event by itself. }\end{array}$ \\
\hline & $\begin{array}{l}\text { Wu et al., } \\
2007\end{array}$ & $\sum_{-1}^{\infty}$ & 을 & 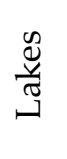 & Empirical & SDD & $\begin{array}{l}\text { Utilizes Landsat and MODIS data to } \\
\text { measure the effect of dredging on } \\
\text { water clarity. }\end{array}$ \\
\hline \multirow{2}{*}{ 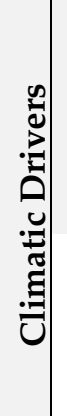 } & $\begin{array}{l}\text { Lymburner } \\
\text { et al., } 2016\end{array}$ & $\delta_{0}^{10}$ & 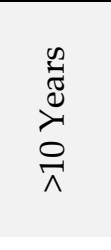 & 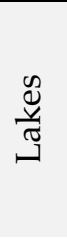 & $\begin{array}{c}\text { Semi } \\
\text { Analytical }\end{array}$ & TSS & $\begin{array}{c}\text { Examines interactions between } \\
\text { decadal climate variations (ENSO) } \\
\text { and TSS concentrations in optically } \\
\text { heterogenous lakes across western } \\
\text { Australia. }\end{array}$ \\
\hline & $\begin{array}{l}\text { Robert et } \\
\text { al., } 2017\end{array}$ & ఏ̊ & 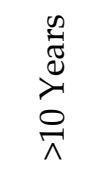 & 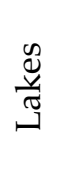 & Empirical & TSS & $\begin{array}{c}\text { Examines climactic drivers of TSS } \\
\text { extremes and seasonal cycles in Mali } \\
\text { lakes. }\end{array}$ \\
\hline
\end{tabular}




\begin{tabular}{|c|c|c|c|c|c|c|}
\hline Author & 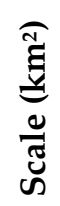 & 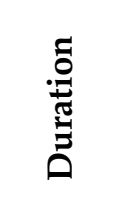 & $\begin{array}{l}\frac{1}{8} \\
0 \\
\frac{0}{0} \\
\frac{1}{\pi} \\
3\end{array}$ & 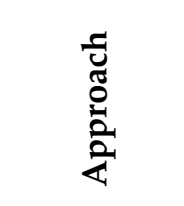 & 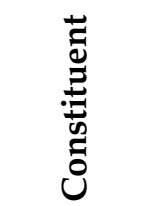 & Analysis Summary \\
\hline $\begin{array}{l}\text { Huang et } \\
\text { al., } 2015\end{array}$ & $\sum_{0}^{\infty}$ & 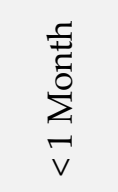 & 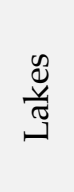 & Empirical & $\begin{array}{l}\text { TSS, } \\
\text { Chl-a, } \\
\text { TP }\end{array}$ & $\begin{array}{l}\text { Examines how the provision of } \\
\text { phosphorous from sediment } \\
\text { resuspension controls TSS and chl-a } \\
\text { dynamics in a shallow lake. }\end{array}$ \\
\hline $\begin{array}{l}\text { Zhang et } \\
\text { al., } 2016\end{array}$ & $\sum_{0}^{\infty}$ & 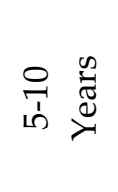 & $\frac{\mathscr{Q}}{\tilde{\sigma}}$ & Empirical & TSS & $\begin{array}{c}\text { Analyzes spatiotemporal dynamics } \\
\text { of river plumes in a shallow lake and } \\
\text { their correlation with rainfall } \\
\text { magnitude. }\end{array}$ \\
\hline $\begin{array}{c}\text { Zhu et al., } \\
2014\end{array}$ & $\sum_{0}^{\infty}$ & 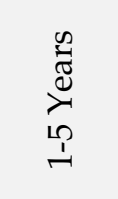 & $\frac{\mathscr{8}}{\tilde{\Xi}}$ & $\begin{array}{c}\text { Semi } \\
\text { Empirical }\end{array}$ & $\begin{array}{c}\text { Algal } \\
\text { Blooms }\end{array}$ & $\begin{array}{l}\text { Examines how typhoon induced } \\
\text { sediment resuspension and nutrient } \\
\text { mixing impact the development } \\
\text { dynamics of algal blooms. }\end{array}$ \\
\hline $\begin{array}{l}\text { Curtarelli et } \\
\text { al., } 2015\end{array}$ & $\vdots^{N}$ & 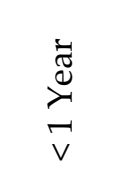 & $\begin{array}{l}\mathscr{\mathscr { Q }} \\
\stackrel{y}{త}\end{array}$ & Empirical & Chl-a & $\begin{array}{l}\text { Combines remote sensing with } \\
\text { hydrodynamic modelling to examine } \\
\text { the role of thermal stratification and } \\
\text { mixing on chl-a dynamics. }\end{array}$ \\
\hline $\begin{array}{c}\text { Matthews, } \\
2014\end{array}$ & $\sum_{0}^{\infty}$ & 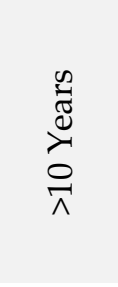 & $\frac{\mathscr{g}}{\tilde{\sigma}}$ & Empirical & Chl-a & $\begin{array}{l}\text { Identifies long term trends in chl-a } \\
\text { and cyanobacteria blooms across } 50 \\
\text { lakes in South Africa. Discusses } \\
\text { how clustering of overarching trends } \\
\text { and lake trophic state follow } \\
\text { biogeophysical landscape properties. }\end{array}$ \\
\hline $\begin{array}{l}\text { Huang et } \\
\text { al., } 2014\end{array}$ & $\sum_{0}^{\infty}$ & 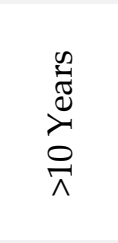 & $\frac{\mathscr{g}}{\tilde{\sigma}}$ & $\begin{array}{c}\text { Semi } \\
\text { Empirical }\end{array}$ & Chl-a & $\begin{array}{l}\text { Examines the role of wind, } \\
\text { precipitation, decadal climate signals, } \\
\text { and resuspension driven nutrient } \\
\text { availability on the } \\
\text { presence/dynamics of algal blooms. }\end{array}$ \\
\hline $\begin{array}{c}\text { Nellis, } \\
\text { Harrington, } \\
\& W u, 1998\end{array}$ & ఏ̊ & 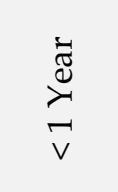 & $\begin{array}{l}\text { 巳 } \\
\text { 亗 }\end{array}$ & $\begin{array}{c}\text { Semi } \\
\text { Analytical }\end{array}$ & TSS & $\begin{array}{l}\text { Examines the impacts of a flood } \\
\text { event on sediment concentration, } \\
\text { pool size, and water quality } \\
\text { dynamics in a Kansas reservoir. }\end{array}$ \\
\hline $\begin{array}{l}\text { Wang et al., } \\
2012\end{array}$ & $\sum_{0}^{\infty}$ & 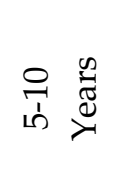 & 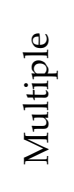 & Empirical & $\begin{array}{l}\text { Turbidi } \\
\text { ty }\end{array}$ & $\begin{array}{l}\text { Examines the role of hurricanes in } \\
\text { controlling turbidity levels in } \\
\text { Florida's Lake Okeechobee and two } \\
\text { connected estuaries. }\end{array}$ \\
\hline
\end{tabular}




\begin{tabular}{|c|c|c|c|c|c|c|c|}
\hline & Author & $\begin{array}{l}\widetilde{\tilde{g}} \\
\underset{\tilde{g}}{\tilde{g}} \\
\tilde{\tilde{J}} \\
\omega\end{array}$ & 节 & $\begin{array}{l}2 \\
0 \\
0 \\
0 \\
\frac{0}{0} \\
3 \\
3\end{array}$ & 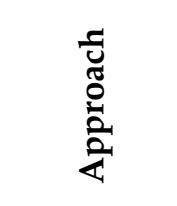 & 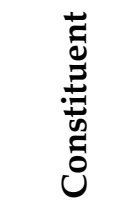 & Analysis Summary \\
\hline & $\begin{array}{l}\text { Ng et al., } \\
2011\end{array}$ & $\underbrace{N}_{-}$ & $\begin{array}{l}\text { むँ } \\
\text { خै } \\
\vec{v}\end{array}$ & $\begin{array}{l}\text { \& } \\
\text { 光 } \\
\text { J }\end{array}$ & $\begin{array}{c}\text { Semi } \\
\text { Empirical }\end{array}$ & Chl-a & $\begin{array}{l}\text { Incorporates remote sensing data } \\
\text { into a 3D hydrological model to } \\
\text { analyze dinoflagellate dispersion } \\
\text { within a lake ecosystem. Finds that } \\
\text { bloom growth is controlled by } \\
\text { stratification while dispersion is } \\
\text { driven by wave forces. }\end{array}$ \\
\hline & $\begin{array}{l}\text { Sass et al., } \\
2008 \mathrm{a}\end{array}$ & $\varliminf_{0}^{\infty}$ & 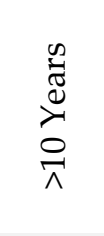 & 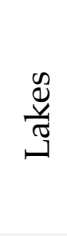 & Empirical & Chl-a & $\begin{array}{l}\text { Examines variations in trophic state } \\
\text { within boreal lakes driven by } \\
\text { climactic variables. Finds that } \\
\text { growing season length and May } \\
\text { temperatures are key drivers. }\end{array}$ \\
\hline & $\begin{array}{c}\text { Bayley et } \\
\text { al., } 2007\end{array}$ & $\bigcup_{0}^{N}$ & 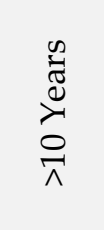 & 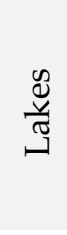 & Empirical & Chl-a & $\begin{array}{l}\text { Tests the 'stable states' hypothesis } \\
\text { regarding trophic status for boreal } \\
\text { lakes and finds that most lakes in the } \\
\text { study area have one dominate state } \\
\text { rather than two. }\end{array}$ \\
\hline & $\begin{array}{l}\text { Feng et al., } \\
2015\end{array}$ & $\dot{S}_{0}^{+}$ & 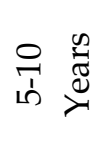 & 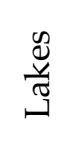 & $\begin{array}{c}\text { Semi } \\
\text { Empirical }\end{array}$ & Chl-a & $\begin{array}{l}\text { Identifies high risk eutrophication } \\
\text { areas and their relationship to } \\
\text { connectivity and precipitation. }\end{array}$ \\
\hline & $\begin{array}{c}\text { Duan et al., } \\
2017\end{array}$ & $\hat{\sigma}^{N}$ & 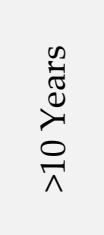 & 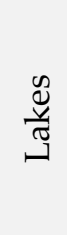 & $\begin{array}{l}\text { Machine } \\
\text { Learning }\end{array}$ & Chl-a & $\begin{array}{l}\text { Analyzes spatiotemporal } \\
\text { distributions of phycocyanin and chl- } \\
\text { a and develops a hazard assessment } \\
\text { map to identify safe areas for } \\
\text { drinking water outlets. }\end{array}$ \\
\hline \multirow{3}{*}{ 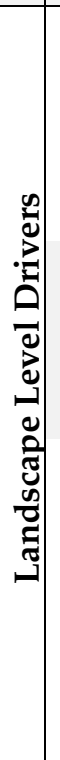 } & $\begin{array}{l}\text { Dvornikov } \\
\text { et al., } 2018\end{array}$ & $\vdots_{0}^{N}$ & 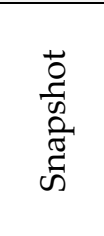 & 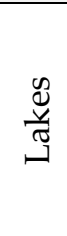 & Empirical & CDOM & $\begin{array}{l}\text { Analyzes landscape level drivers of } \\
\text { CDOM in arctic lakes and finds } \\
\text { significant relationships between } \\
\text { thermocirque presence and elevated } \\
\text { CDOM levels. }\end{array}$ \\
\hline & $\begin{array}{l}\text { Sass et al., } \\
2008 \mathrm{~b}\end{array}$ & $\sum_{0}^{\infty}$ & 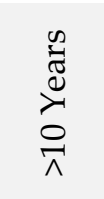 & $\begin{array}{l}\mathscr{d} \\
\stackrel{\sigma}{\sigma}\end{array}$ & Empirical & Chl-a & $\begin{array}{c}\text { Examines connectivity, wetland area, } \\
\text { and concentrations of } \mathrm{Ca} \text { and } \mathrm{Mg} \\
\text { that control the trophic state of boreal } \\
\text { lakes. }\end{array}$ \\
\hline & $\begin{array}{l}\text { Rose et al., } \\
2017\end{array}$ & 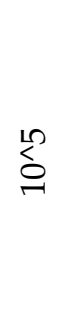 & 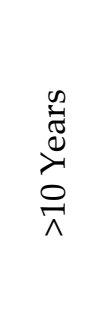 & 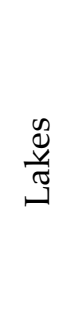 & Empirical & SDD & $\begin{array}{l}\text { Examines how watershed and } \\
\text { riparian zone characteristics drive } \\
\text { water clarity and finds that during } \\
\text { wet years, watershed scale drivers } \\
\text { dominate while for dry years } \\
\text { riparian characteristics are more } \\
\text { important. }\end{array}$ \\
\hline
\end{tabular}




\begin{tabular}{|c|c|c|c|c|c|c|c|}
\hline & Author & 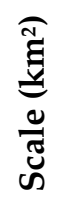 & 龸 & $\begin{array}{l}\overrightarrow{2} \\
0 \\
\frac{0}{2} \\
\frac{0}{2} \\
3 \\
3\end{array}$ & 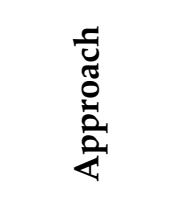 & 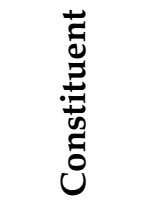 & Analysis Summary \\
\hline \multirow{3}{*}{ 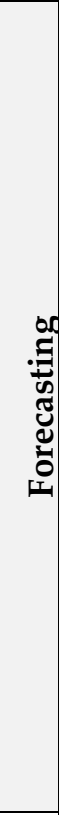 } & $\begin{array}{l}\text { Qin et al., } \\
2015\end{array}$ & $\sum_{0}^{\infty}$ & 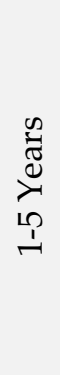 & 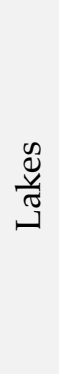 & Empirical & Chl-a & $\begin{array}{l}\text { Develops a dynamic forecasting } \\
\text { model incorporating wind, } \\
\text { precipitation, and remotely sensed } \\
\text { chl-a concentration to predict algal } \\
\text { bloom development in Lake Taihu, } \\
\text { China. The applied model helped } \\
\text { remove over 1,000,000 tons of algal } \\
\text { scum from the lake. }\end{array}$ \\
\hline & $\begin{array}{l}\text { Imen et al., } \\
2015\end{array}$ & $\sum_{0}^{\infty}$ & 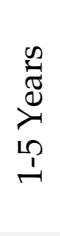 & 造 & $\begin{array}{l}\text { Machine } \\
\text { Learning }\end{array}$ & TSS & $\begin{array}{l}\text { Utilizes remotely sensed TSS data to } \\
\text { construct a real-time forecasting } \\
\text { model for predicting degraded water } \\
\text { quality near drinking water outlets in } \\
\text { Lake Mead. }\end{array}$ \\
\hline & $\begin{array}{l}\text { Zhang et } \\
\text { al., } 2013\end{array}$ & $\sum_{0}^{\infty}$ & 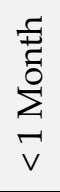 & $\frac{\mathscr{U}}{\frac{\pi}{త ్}}$ & Mixed & Chl-a & $\begin{array}{c}\text { Develops forecasting model capable } \\
\text { of predicting algal blooms 3-5 days in } \\
\text { advance in shallow Lake Taihu in } \\
\text { China. }\end{array}$ \\
\hline \multirow{5}{*}{ 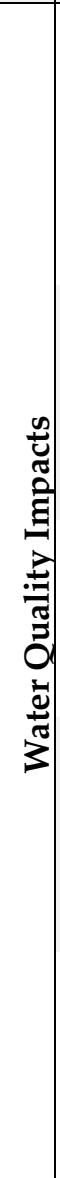 } & $\begin{array}{l}\text { Sandström } \\
\text { et al., } 2016\end{array}$ & $\sum^{\infty}$ & 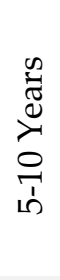 & 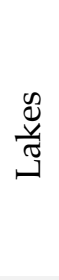 & Product & Chl-a & $\begin{array}{l}\text { Utilizes remotely sensed water } \\
\text { quality parameters to identify and } \\
\text { explain variations in fish habitat and } \\
\text { species composition. Found that } \\
\text { habitat was highly correlated with } \\
\text { CDOM and chl-a levels. }\end{array}$ \\
\hline & $\begin{array}{l}\text { Torbick et } \\
\text { al., } 2014\end{array}$ & 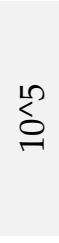 & 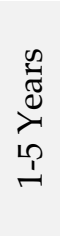 & 造 & Empirical & Chl-a & $\begin{array}{l}\text { Examines distribution of algal } \\
\text { blooms in relation to reported cases } \\
\text { of amyotrophic lateral sclerosis (ALS) } \\
\text { to identify high risk areas for the } \\
\text { disease. }\end{array}$ \\
\hline & $\begin{array}{l}\text { Potes, } \\
\text { Costa, \& } \\
\text { Salgado, } \\
2012\end{array}$ & న̂ & 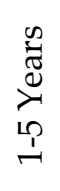 & 岂 & Empirical & $\begin{array}{c}\text { Turbidi } \\
\text { ty }\end{array}$ & $\begin{array}{l}\text { Incorporates remotely sensed } \\
\text { turbidity into a two-layer bulk model } \\
\text { to predict surface water temperature. }\end{array}$ \\
\hline & $\begin{array}{c}\text { Finger et } \\
\text { al., } 2014\end{array}$ & $\sum_{0}^{\infty}$ & 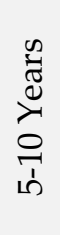 & 岂 & Product & Chl-a & $\begin{array}{l}\text { Incorporates remotely sensed chl-a } \\
\text { data into a model examining the } \\
\text { dynamics and drivers of cholera } \\
\text { outbreaks in the Democratic } \\
\text { Republic of Congo. }\end{array}$ \\
\hline & $\begin{array}{c}\text { Pavelsky } \\
\text { and Smith, } \\
2009\end{array}$ & $\sum_{0}^{m}$ & $\begin{array}{l}\stackrel{\vec{\Xi}}{\beth} \\
\vec{v}\end{array}$ & $\underset{\frac{\grave{d}}{\tilde{d}}}{\frac{\vec{d}}{\sigma}}$ & Empirical & TSS & $\begin{array}{l}\text { Utilizes remotely sensed TSS } \\
\text { concentration to examine river } \\
\text { velocity, flow reversal, and } \\
\text { hyrodologic recharge of floodplain } \\
\text { lakes in the Peace-Athabasca Delta. }\end{array}$ \\
\hline
\end{tabular}




\begin{tabular}{|c|c|c|c|c|c|c|c|}
\hline & Author & 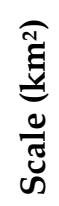 & مُ & $\begin{array}{l}\frac{1}{0} \\
0 \\
\frac{0}{\pi} \\
\frac{1}{\pi} \\
3\end{array}$ & 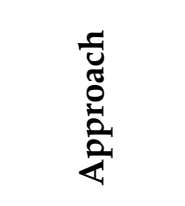 & 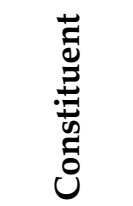 & Analysis Summary \\
\hline & $\begin{array}{l}\text { Telmer et } \\
\text { al., } 2006\end{array}$ & 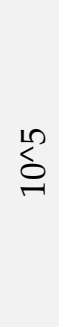 & 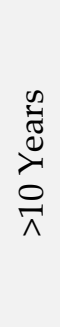 & 营 & Empirical & TSS & $\begin{array}{l}\text { By using the correlation between TSS } \\
\text { and mercury, the authors present a } \\
\text { remote estimation of mercury } \\
\text { concentrations, which they use to } \\
\text { examine likely drivers of increased } \\
\text { mercury concentrations from gold- } \\
\text { mining. }\end{array}$ \\
\hline & $\begin{array}{l}\text { Overeem et } \\
\text { al., } 2017\end{array}$ & $\sum_{-}^{+1}$ & 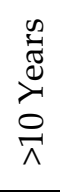 & : & Empirical & TSS & $\begin{array}{l}\text { Examined flux of suspended } \\
\text { sediment from Greenland ice sheet, } \\
\text { highlighting disproportionately high } \\
\text { global contribution of sediment. }\end{array}$ \\
\hline \multirow{3}{*}{ 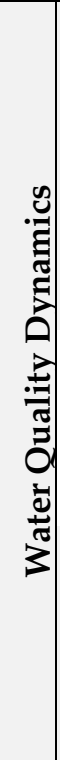 } & $\begin{array}{l}\text { Griffin et } \\
\text { al., } 2011\end{array}$ & $\underbrace{+1}_{0}$ & 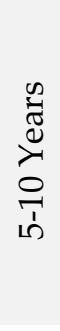 & : & Empirical & CDOM & $\begin{array}{l}\text { Used remote sensing of CDOM and } \\
\text { DOC to highlight the interannual } \\
\text { variability of both, while also } \\
\text { highlighting that the spatial and } \\
\text { temporal variability likely causes } \\
\text { underestimates of DOC flux from } \\
\text { Kolyma River. }\end{array}$ \\
\hline & $\begin{array}{c}\text { Walker, } \\
1996\end{array}$ & $\sum_{-1}^{n}$ & 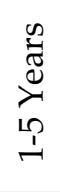 & 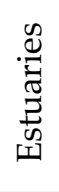 & $\begin{array}{c}\text { Semi } \\
\text { Analytical }\end{array}$ & TSS & $\begin{array}{l}\text { With remote sensing estimates of } \\
\text { suspended sediments, Walker } \\
\text { explores causes of plume variability } \\
\text { in the Mississippi River. }\end{array}$ \\
\hline & $\begin{array}{c}\text { Falcini et } \\
\text { al., } 2012\end{array}$ & $\underbrace{+1}_{0}$ & 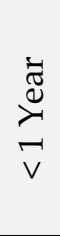 & 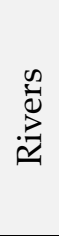 & Product & TSS & $\begin{array}{l}\text { Used remote estimates of TSS to } \\
\text { examine sedimentation in wetlands } \\
\text { and link them to hydrodynamics } \\
\text { with implications for wetland } \\
\text { restoration }\end{array}$ \\
\hline
\end{tabular}

1416 Table S2. Summary of studies using remote sensing to analyze impacts and drivers of water quality and classified as water quality science papers within the analysis. 